
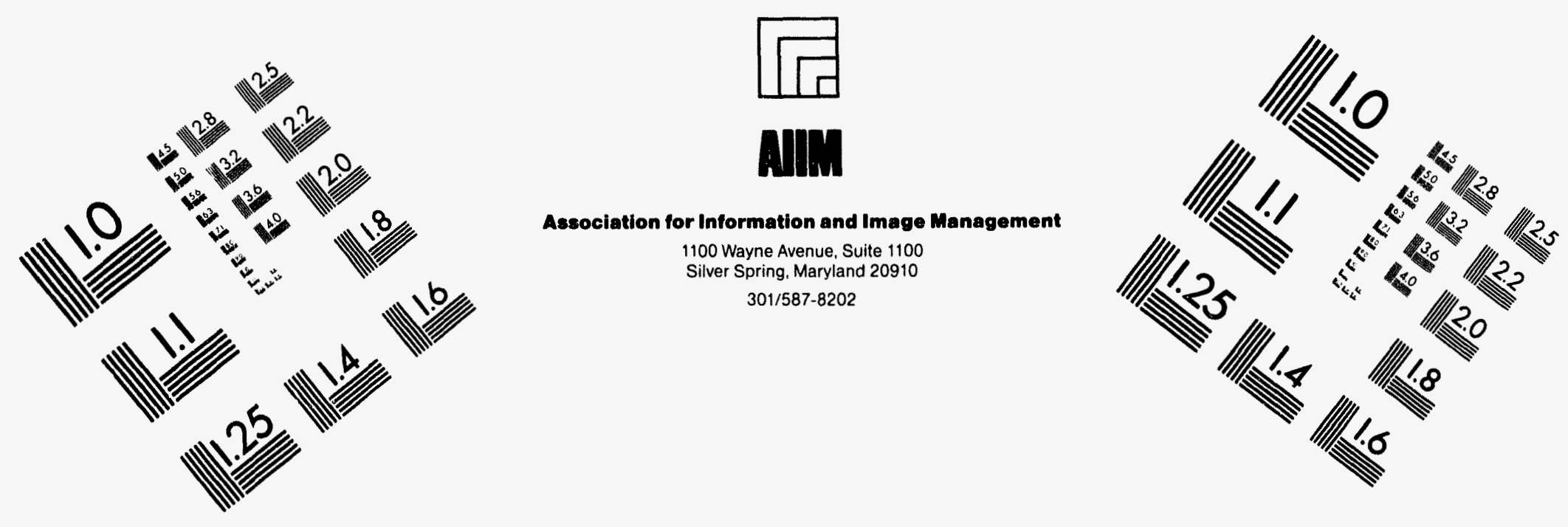

\title{
Centimeter
} ${ }_{1}$ Inches
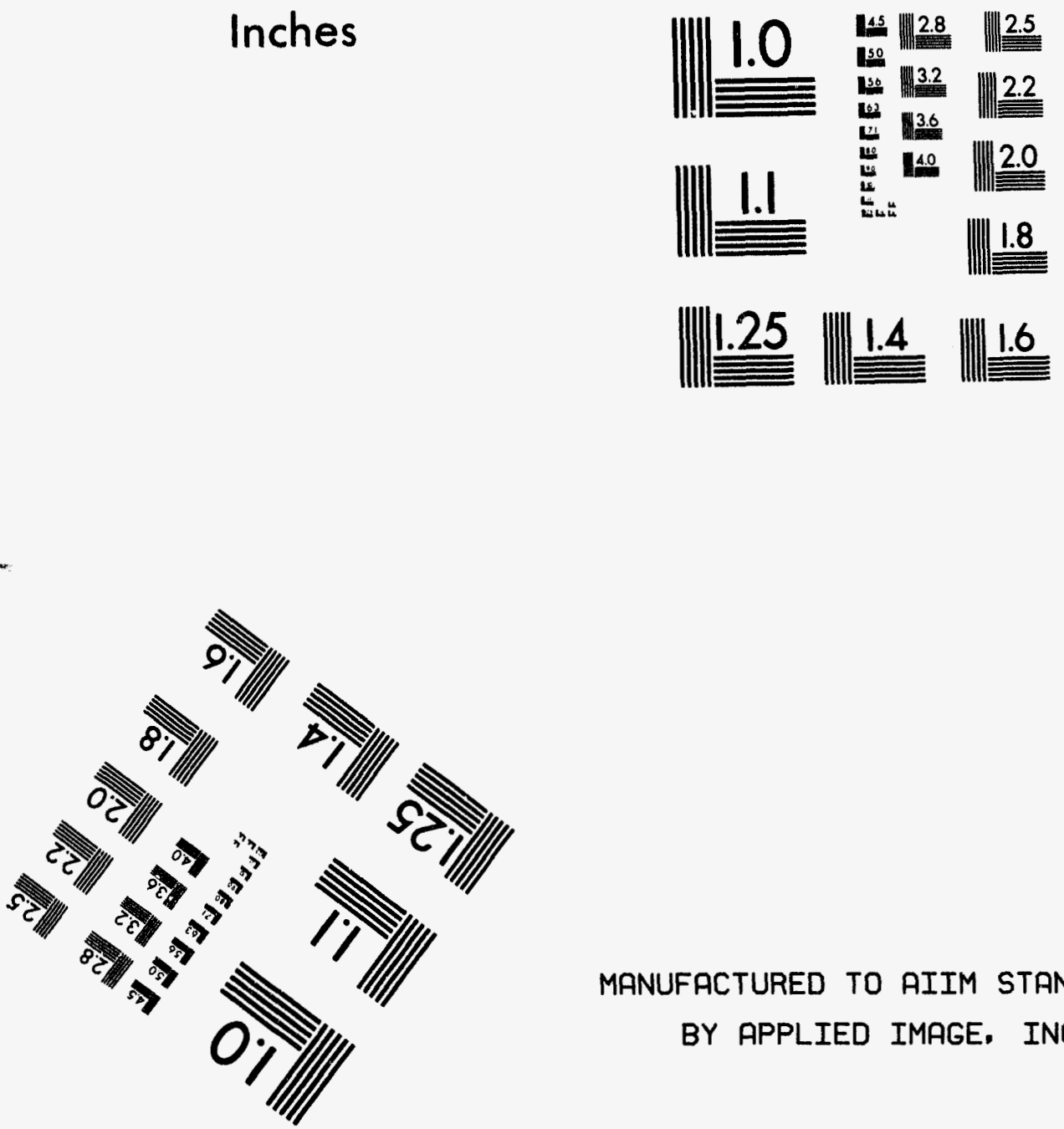

MANUFACTURED TO AIIM STANDARDS

BY APPLIED IMAGE, INC.

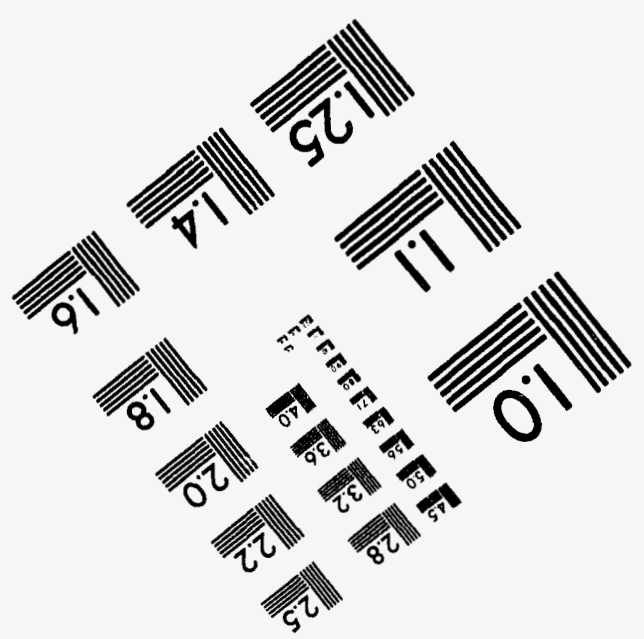



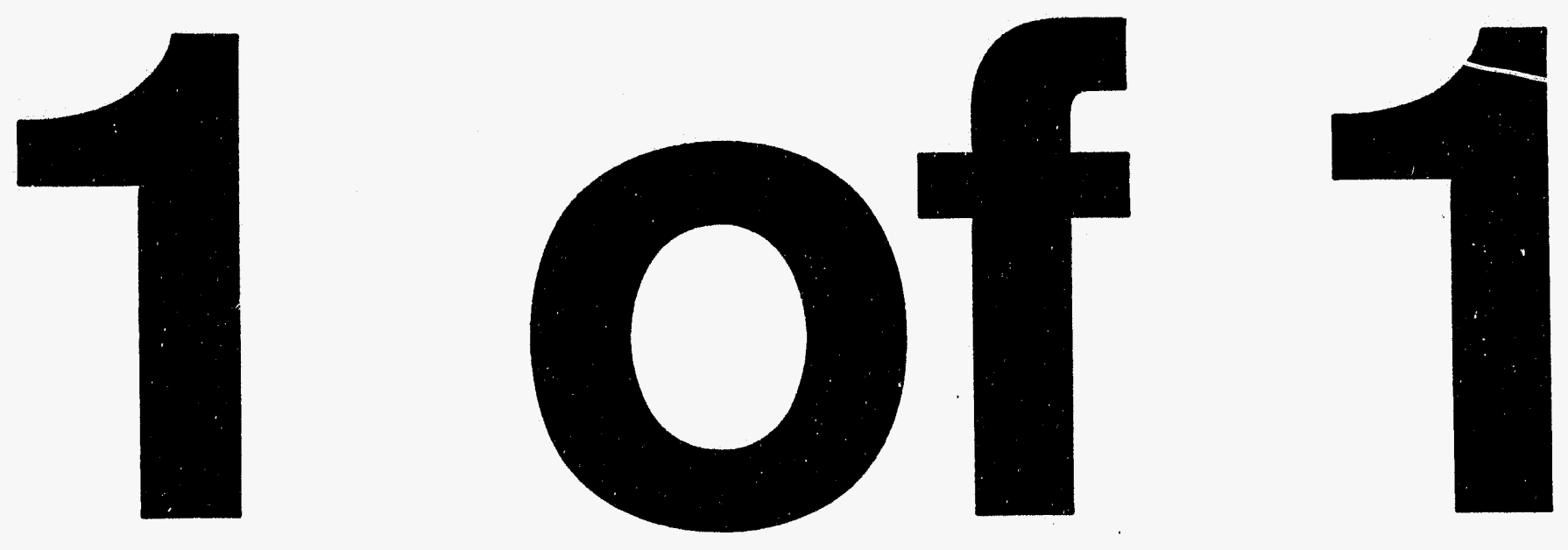


\section{The Effects of Stress on}

Nuclear Power Plant

Operational Decision Making and

Training Approaches to

Reduce Stress Effects

Manuscript Completed: June 1994

Date Published: August 1994

Prepared by

R. J. Mumaw

I. Schoenfeld, NRC Project Manager

Westinghouse Electric Corporation

1310 Beulah Road

Pittsburgh, PA 15235

Prepared for

Division of Systems Research

Office of Nuclear Regulatory Research

U.S. Nuclear Regulatory Commission

Washington, DC 20555-0001

NRC FIN L1653 


\begin{abstract}
Operational personnel may be exposed to significant levels of stress during unexpected changes in plant state and plant emergencies. The decision making that identifies operational actions, which is strongly determined by procedures, may be affected by stress, and performance may be impaired. This report analyzes potential effects of stress in nuclear power plant (NPP) settings, especially in the context of severe accident management (SAM). First, potential sources of stress in the NPP setting are identified. This analysis is followed by a review of the ways in which stress is likely to affect performance, with an emphasis on performance of cognitive skills that are linked to operational decision making. Finally, potential training approaches for reducing or eliminating stress effects are identified.
\end{abstract}

Several training approaches have the potential to eliminate or mitigate stress effects on cognitive skill performance. First, the use of simulated events for training can reduce the novelty and uncertainty that can lead to stress and performance impairments. Second, training to make cognitive processing more efficient and less reliant on attention and memory resources can offset the reductions in these resources that occur under stressful conditions. Third, training that targets crew communications skills can reduce the likelihood that communications will fail under stress. 


\section{Table of Contents}

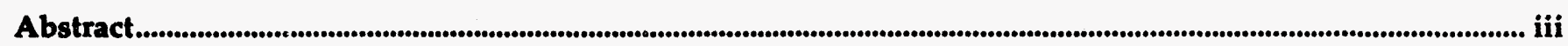

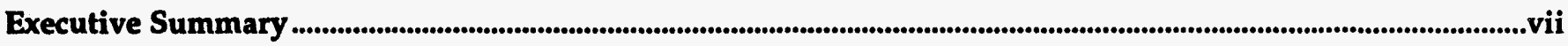

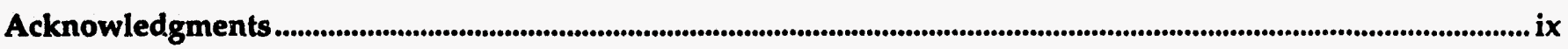

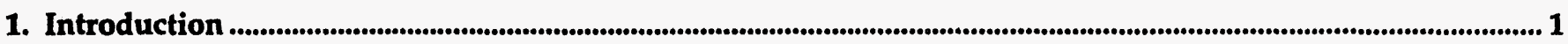

2. Stress and Performance: A Review of the Literature.................................................................................................. 3

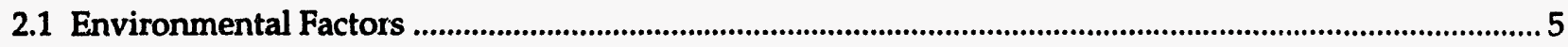

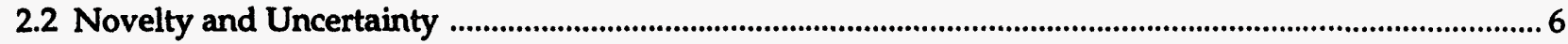

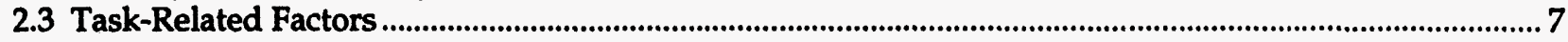

2.4 Impairment Due to Stress on Cognitive Task Performance ................................................................................ 7

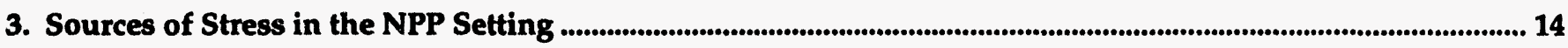

3.1 Environmental Factors as Sources of Stress in NPP Operations............................................................... 14

3.2 Novelty and Uncertainty as Sources of Stress in NPP Operations............................................................... 16

3.3 Task-Related Factors as Sources of Stress in NPP Operations ....................................................................... 17

4. Stress Effects on Performance of Cognitive Tasks............................................................................................................................ 19

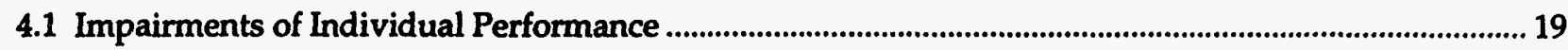

4.2 Impairments of Crew Performance .................................................................................................................... 21

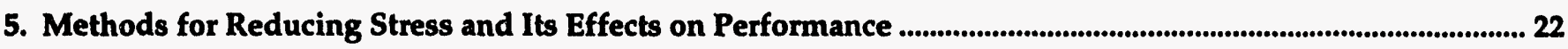

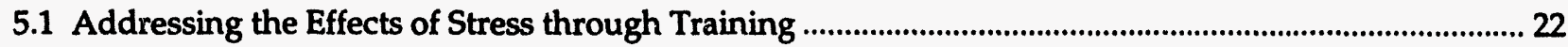

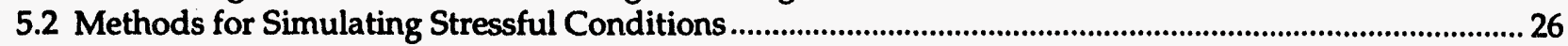

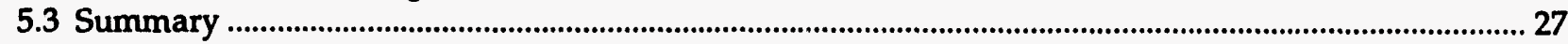

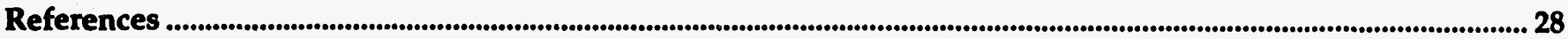




\section{List of Figures}

Figure 1a. Yerkes-Dodson general inverted-U relationship between arousal and performance.

Figure 1b. Inverse relationship between task difficulty and optimal arousal level.

Figure 2. Typical time-accuracy trade-off for simple task ................................................................................................... 10

\section{List of Tables}

Table 1. Summary of high-level cognitive skills needed for NPP decision making..................................................... 15

Table 2. Potential sources of stress in an NPP setting... 


\section{The Effects of Stress on Nuclear Power Plant Operational Decision Making and Training Approaches to Reduce Stress Effects}

\section{Executive Summary}

Stress has been identified as a significant influence on human performance for decades and has been studied across a broad set of research efforts. High levels of stress are associated with control room decision making tasks required for nuclear power plant (NPP) operations. Recent attention to the development of guidance documents for responding to severe accidents has prompted the question of how stress might affect performance during complex decisionmaking tasks. The U.S. Nuclear Regulatory Commission supported a research project that analyzed severe accident management (SAM) decision making, the cognitive skills likely to be important to decision making, and training approaches for developing those skills. This report describes the component of that project that addresses potential sources of stress in NPP settings, the results of a literature review on the effects of stress on performance, specific NPP decision-making skills that are likely to be affected by stress, and potential training approaches for reducing or eliminating the negative effects of stress.

Three distinct approaches to defining stress in general were considered in the identification of potential sources of stress in the NPP environment. The first approach considers environmental factors that contribute to stress. The primary sources identified are high heat, poor lighting, encumbrance of protective clothing, noise, and fatigue caused by prolonged work, sudden changes in work shift, or loss of sleep. The second approach addresses the role of novelty and uncertainty in producing stress; primary sources here are the occurrence of a novel event, a violation of expectations, loss of critical information, and a failed implementation of a plan or control action. Finally, task-related factors that contribute to stress are considered. Additional sources identified from this approach are high workload, time pressure, and performance anxiety due to safety consequences.
The stress literature identifies the effects of stress primarily from a physiological response: either generally described as increased arousal or more specifically identified in terms of changes in the endocrine system. A state of heightened arousal is believed to have consequences tied to physical health, emotions, and performance. This report focuses only on the effects of stress on performance and specifically addresses impairments of performance of cognitive or decision-making skills. A review of the literature indicated that stress can lead to the following types of performance impairments:

- A narrowing and shift in attentional focus.

- A reduced working memory capacity.

- Time pressure effects.

- Impaired crew communication patterns.

A wide range of cognitive skills needed in NPF decision making during SAM conditions--including elements of monitoring, situation assessment, planning, and execution--are affected by these impairments. However, there are several training techniques that have the potential to eliminate or mitigate the effects of stress on the performance of cognitive skills:

- Expose the crew to realistic severe accident events through simulation. Realistic simulation can aid personnel in developing expectations about the event, skills for controlling the event, and skills for obtaining feedback concerning the success of control actions. This approach primarily removes novelty and uncertainty, which are likely to be major contributors to stress.

- Reduce the demand on mental resources and make processing more efficient. A number of training techniques exist that can make personnel more efficient information processors and, thereby, reduce the demands on attention and working memory.

- Enhance crew communication and coordination skills. Crew training techniques have been refined that have been successfully used for enhancing crew skills, especially skills for 
communication. These skills target the types of communication failures that are likely to occur under stress.

In general, the training approaches presented attempt to develop more highly skilled personnel. When the necessary cognitive skills become mastered at a high level of performance, there is less reliance on memory and attention resources and personnel are less susceptible to the likely effects of stress (i.e., task performance is less likely to be degraded under stressful operating conditions). Other positive outcomes can also be gained from these training approaches:

- Novelty and uncertainty are removed or greatly reduced.

- Operators and technical staff better understand what effect their control actions will have.

- Operators and technical staff can better cope with (and maybe stay ahead of) task demands.

- The crew shares and uses critical information better.

- There is generally a stronger feeling of control.

Thus, while all of the factors that can lead to a stressful reaction may not be eliminated, training may reduce performance impairments significantly so that decision making can be executed efficiently and effectively. 


\section{Acknowledgments}

The author wishes to take this opportunity to thank Isabelle Schoenfeld and J.J. Persensky of the Human Factors Branch, Office of Nuclear Regulatory Research, for defining and maintaining the overall program objectives and ensuring that our project deliverables remained responsive to NRC's needs. Isabelle strongly influenced the organization and direction of the project reports (this report and NUREG/CR-6126). Further, Isabelle ensured that we coordinated our activities appropriately with relevant efforts in the Office of Nuclear Reactor Regulation (NRR) at the NRC.

It is also important to acknowledge the efforts of several reviewers who provided valuable comments on earlier drafts: David DeSaulniers of the Human Factors Assessment Branch, NRR; Emilie Roth of Westinghouse; and Valerie Barnes. 


\section{The Effects of Stress on Nuclear Power Plant Operational Decision Making and Training Approaches to Reduce Stress Effects}

\section{Introduction}

The effects of stress on mind and body have received attention in American society for decades. The extensive literature on stress--spanning fields such as medicine, psychology, management, etc.-identifies concerns that range from long-term health risks to transitory impairments of human performance. Industry attention to the design of an effective response to severe accidents, and the more general issue of severe accident management (SAM), has prompted the question of how stress might affect performance during complex decision-making tasks. In particular, SAM decision making may rely more on knowledge-based performance because procedural guidance may be less prescriptive, and it may force greater reliance on communication and coordination among groups (control room and Technical Support Center staff) to develop an appropriate response. These characteristics are likely to make SAM decision making especially susceptible to the effects of stress.

The U.S. Nuclear Regulatory Commission (NRC) supported a research project, which was conducted by Westinghouse Science \& Technology Center, that analyzed SAM decision making, the cognitive skills likely to be important to decision making, and training approaches for developing these skills. The details and results of that project are described in NUREG/CR-6126 ("Cognitive Skill Training for Nuclear Power Plant Operational Decision Making"). This report describes a component of that project, defined by the following objectives:

- Identify the potential sources of stress in the NPP setting, especially in the context of SAM operations.

- Review the research literature to determine how stress is likely to affect performance in general and, more specifically, performance of cognitive skills associated with decision making.
- Identify specific decision-making skills that are likely to be negatively affected by stress.

- Review the research and training literature to identify potential approaches for reducing or eliminating the negative effects of stress.

Primary potential sources of stress during SAM operations are the physical environment, the element of uncertainty or novelty in the unfolding events, and task-related factors such as workload. A review of the research literature on stress and performance suggests a number of ways that NPP decision making can be affected. First, stress-related decrements in attention may reduce the effectiveness of plant state monitoring, control execution and management, and the monitoring of indications to determine that control actions are effective. Second, impairments to working memory reduce a decision maker's ability to develop a situation assessment of plant state, assess the effectiveness of procedures and plans, and coordinate control actions. Third, stress can cause operators to behave as though there is time pressure, which can lead to less concern for accuracy and thoroughness in all decision-making activities. Finally, crew communications can break down under stress so that critical information is not passed from the crew to the decision maker effectively. While efforts should be taken to anticipate and reduce the potential sources of stress, training solutions are also available to make decision-making performance less susceptible to stress effects.

This report identifies models, concepts, and empirical findings that can lead to a greater understanding of the effects of stress on the cognitive skills used in NPP decision making. Several training approaches are then proposed for minimizing the effects of stress on NPP task performance.

The report is organized as follows: Section 2 provides a broad review of the research literature on stress and performance, covering issues such as the general effects of stress on human performance, 
Training Approaches to Reduce Stress Effects

approaches for defining stress, and specific performance impairments in cognitive task

performance. Section 3 discusses the likely sources of stress in SAM situations. Section 4 identifies cognitive skills associated with NPP decision making and specifies how those skills are likely to be affected by specific impairments due to stress.

Section 5 addresses techniques for reducing sources of stress and for training personnel to better cope with stress that cannot be eliminated. 


\section{Stress and Performance: A Review of the Literature}

Performance impairments are the primary focus of this report, especially impairments associated with decision-making in the SAM setting. Because SAM decision-making tasks rely strongly on cognitive skills, it is important to understand the types of impairments due to stress that may affect cognitive skills. This section summarizes the broad literature on stress and the types of performance impairments attributed to stress.

A general performance impairment attributed to stress was identified quite early in the literature by Selye (1936). Selye, in studying animals exposed to environmental stressors, such as cold and injury, developed the concept of a "general adaptation syndrome." Although this concept was based on findings from animals, it was intended to apply equally to humans. Selye described this syndrome as a set of physiological responses (e.g., rapid decrease in size of the thymus, loss of muscle tone) that occur, and he characterized the response as a "generalised effort of the organism to adapt itself to new conditions." (p.32)

Selye's notion has been replaced over the years by two different characterizations of the physiological response to stress. One of these (Levine, 1988) emphasizes changes in the endocrine system, especially increased secretion of catecholamines and increased activation of the pituitary-adrenal system, which occur in response to specific stimuli. The second characterization of the stress response (Hockey, 1979) associates stress to the more general notion of increased arousal or activation of the central nervous system. The arousal concept plays a primary role in discussions of the effects of stress on performance.

Arousal was established as a central concept through the well-known demonstration by Yerkes and Dodson (1908), which has become a cornerstone of theories of performance under stress. Yerkes and Dodson studied the effects of electric shock on discrimination learning in mice. Increases in the strength of the shock led to faster acquisition of the easiest discrimination tasks, but as the discrimination task became more difficult, the level of shock that produced the fastest learning was progressively reduced. This result has become more generally expressed as the following two postulates:

1. For any task, there is an optimal level of arousal such that performance level falls off at both lower and higher levels of arousal. This is the general inverted-U function (see Figure 1a).

2. The optimal level of arousal is inversely related to task difficulty, such that performance of simple tasks is optimal at higher levels of arousal and performance of difficult tasks is optimal at lower levels of arousal (see Figure 1b).

Thus, the stress literature associates stress primarily with a physiological response: either generally described as arousal or more specifically identified in terms of changes in the endocrine system.

Heightened arousal associated with stress is believed to have three consequences: impairments of physical health, emotion, and performance (Lazarus, 1966; Novaco, 1988). The first of these is tied to long-term effects of chronic stress. The pronounced physiological activation from stress constitutes a disturbance to physiological systems. Long-term exposure to this arousal is thought to be related to disease processes that affect the internal organs and the skeletal musculature. This report is more concerned, however, with stressful situations that have a short term and sudden onset than on long-term effects of stress. The remaining two stress effects are of this nature.

The first of these is tied to emotion. Physiological arousal leads to disruptive emotional states and their maladaptive consequences. Fear (anxiety) and anger constitute emotional states that are linked to maladaptive behavior patterns. For example, anxiety can lead to recurrent avoidance and disorganization of learned behavior patterns (skills). This type of behavior can be detrimental when a systematic decision-making process is required to deal with a severe plant upset. Extreme emotional responses have the potential to disrupt a crew's ability to identify and execute the appropriate control actions.

The other consequence of heightened arousal, in a short-term or sudden-onset situation, is performance impairment, as established by the Yerkes-Dodson 


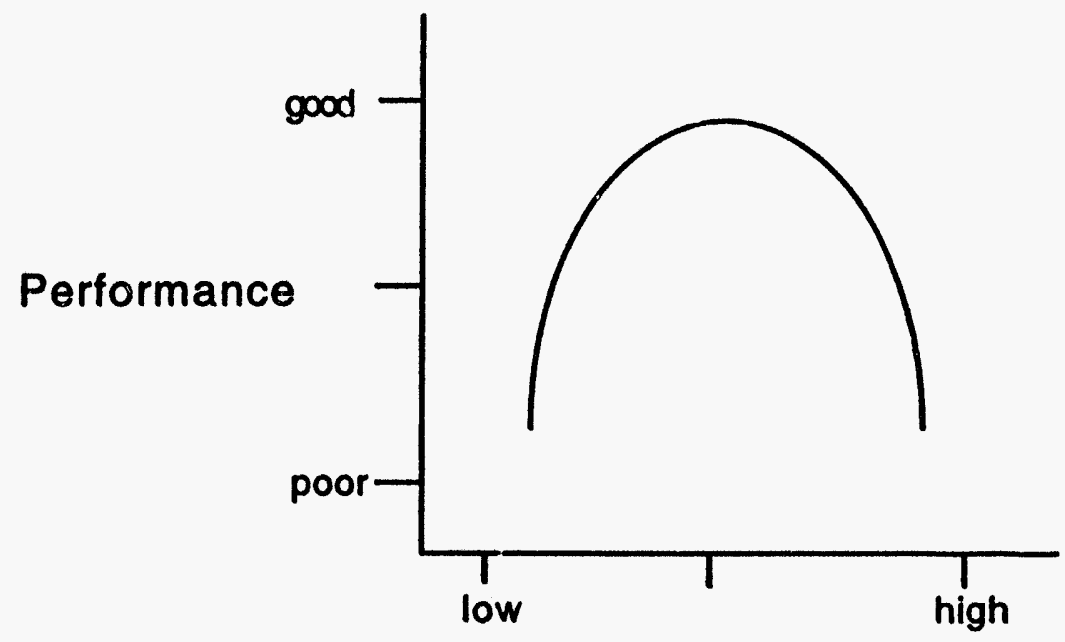

Physiological Arousal

Figure 1a. Yerkes-Dodson general inverted-U relationship between arousal and performance.

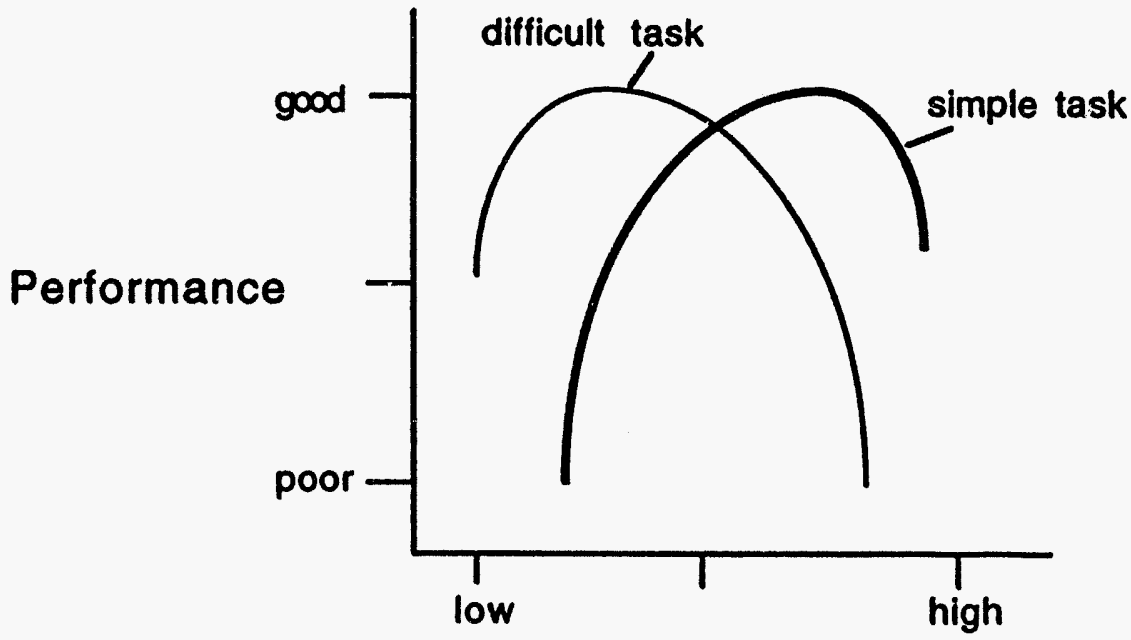

Physiological Arousal

Figure 1b. Inverse relationship between task difficulty and optimal arousal level. 
relationship (although recall that performance is facilitated by arousal in some cases). However, specific aspects of performance impairment are often determined by the source of stress. The literature review identified three approaches for defining stress. The first approach considers environmental factors that lead to stress. The second approach addresses the role of novelty and uncertainty in producing stress. The third approach considers taskrelated factors, such as workload, that contribute to stress.

\subsection{Environmental Factors}

Early approaches for defining stress (e.g., Selye, 1936) emphasized the physical and chemical aspects of environmental stimuli and their associated physiological responses. Environmental factors are still considered important sources of stress in many studies. In a review of the literature, Hockey (1986) developed a stressor classification scheme that emphasizes stressors within the environment, both external (surrounding environment) and internal (the environment within the body). The five classes are:

- physical environment

- drug effects

- fatigue states

- cyclical changes

- social environment

Physical environment encompasses and includes factors such as noise, heat and cold, vibration, lighting, and atmospheric conditions. Noise and heat are the two physical factors most relevant to the NPP environment. Noise is typically defined as unwanted sound or sound that is unrelated to the task being performed. The majority of studies have focused on the effects of continuous, broad-band noise (typically with a sound pressure level greater than $80 \mathrm{~dB}$ ). These studies have tied this type of noise to impaired performance in difficult vigilance tasks (Broadbent, 1979), increased errors in simple response tasks (Broadbent, 1957), and poorer performance in certain memory tasks. Other studies have looked at intermittent noise, which is more similar to the auditory stimulation likely to occur in NPP operations (e.g., alarms). The impairments of performance tied to intermittent noise are described as distraction. That is, a "startle" response, which is associated with a number of physiological changes, inhibits information processing activities. Although alarms are "noises" that are related to the task, and therefore not within the traditional definition of noise, they may still produce a startle response when they are unexpected.

Heat stress has been studied in a less systematic manner, partly due to the variety of means used for measuring ambient heat (combinations of temperature, humidity, air speed, etc.). In general, increases in body temperature are detrimental to task performance.

The next three classes of environmental stressors to be considered have an origin internal to the human. Drug effects, fatigue states, and cyclical changes are internal determinants of physiological state. Hockey (1986) indicates that, in general, drug studies of performance have addressed overall performance impairment or facilitation and have seldom investigated task-specific effects. Generally, stimulants (e.g., caffeine, nicotine, amphetamines) facilitate task performance, and depressants (e.g., alcohol, barbiturates) impair it, regardless of the task. These studies have included both drugs that are part of a course of medication (e.g., anti-anxiety treatments) and drugs that have become common to everyday life for many individuals (e.g., nicotine, caffeine, and alcohol).

Another environmental stressor, fatigue states, has received much attention. Workers--through lengthy periods of sleep deprivation or disruption, or through boredom or long periods of performance (24 hours and longer)--can suffer deficits in performance from fatigue. The area of most interest for NPP operations is probably prolonged work. In one related study, Bartlett (1943) investigated the effects of prolonged performance on piloting skills. One of the main results identified changes in attention. Over time, less attention was paid to peripheral instruments. Also, there are often increases in the variability and the timing of actions with prolonged performance.

The third internal origin of stress are cyclical changes--regular, periodic changes in hormonal levels, alertness, body temperature, etc.--both throughout the day and over longer periods. Certain aspects of task performance are tied to these 
changes. The research literature is too diverse to summarize easily, but a number of studies have identified impairments in memory and attention tasks that are strongly correlated to cyclical changes. Also, shifts from the standard work pattern, such as changes in work shift or changes in time zone, can impair performance.

The fifth class in Hockey's stressor classification scheme are factors from the social environment. In this class, Hockey is most concerned with performance anxiety (pressure to perform well during an evaluation) and the use of incentives (rewards for good performance). Hockey acknowledges that these social factors (as well as physical factors to a lesser degree) are mediated through a "cognitive appraisal" before their weight as a stressor is determined. That is, the level of stress is not totally determined by the presence of environmental stressors, but by the individual's judgment of the importance of that stressor. The next section addresses these psychologically mediated stressors in order to distinguish them from the more direct effects of environmental stressors that are physical and chemical in nature.

\subsection{Novelty and Uncertainty}

Early investigations of stress were concerned with physical stressors in the environment. However, results of these studies revealed large individual differences in response to a given physical stressor, and it became clear that these differences could best be explained with cognitive mechanisms. That is, individuals could learn to adapt to stressors and reduce their effects. Eventually, focus began to shift to the psychological components of stress-the "cognitive appraisal" that Hockey (1986) identified as a component of the effects of both physical and social stressors. It became more evident that a subject's perception of the stressor as a threat largely determined the degree of physiological response.

The psychological mediators that were found to be most critical to physiological response were novelty and uncertainty. Novelty refers generally to events that have not been experienced before and are perceived to have potential risks. Uncertainty refers to an inability to know how an event will progress or be resolved. In general, humans prefer situations that are familiar and outcomes that can be anticipated.

Novelty has been shown to produce increases in pituitary-adrenal activity in both humans and animals. First-time occurrences-having blood drawn at a blood bank or taking the first parachute jump off a tower-can produce dramatic elevations in adrenocortical activity that are not found in subsequent exposures (Levine, 1978). Novelty of this type is tied to uncertainty. That is, if the situation is novel, expectations about likely outcomes do not exist. However, there is a second sense of uncertainty that seems more powerful and has attracted a great deal of attention in the psychological stress liter ature: the inability to predict the occurrence of events.

One experimental paradigm became well-known from the work done by Seligman (1975) in the area of "learned helplessness" (see also Dess et al., 1983). This paradigm places an animal in a situation where an electric shock will be delivered. For some animals, a tone preceded the shock so that its occurrence could be anticipated. For the other animals, there was no means for predicting the onset of the shock. The animals with the ability to predict the shock showed a greatly reduced adrenocortical response, even when there was no means for escaping the shock. Similar findings have been found in research with humans as well: an ability to predict aversive stimuli reduces stress (e.g., Hiroto, 1974). Changes in reinforcement contingencies may also induce a stress response. For example, Coe et al. (1983) trained rats to use a leverpress response to consistently obtain water. When the water was no longer available following the lever-press response, the rats showed a dramatic physiological stress response. A similar response was found in rats when their ability to avoid an aversive stimulus was frustrated in some way (Coover et al., 1973).

Novelty and uncertainty are not only tied to animal behavior. Mandler (1979) has brought this notion into the context of human cognition with his "interruption theory." This theory posits that any interruption of an organized action or thought process causes increased autonomic activity (arousal). Thus, reinforcement schedules, behavioral patterns, or expectancies represent some degree of organization of behavior, which is defined broadly to include both 
cognitive behavior and more overt behaviors. Interruption of these organizations produces arousal. Mandler cites unusual or unexpected (i.e., novel, uncertain) events as the type of events considered to be interruptive, and therefore, events that lead to stress. Mandler provides several examples of these interruptive events, including novel problem solving situations and plans that fail to be implemented.

\subsection{Task-Related Factors}

A third approach to defining stress focuses on task demands. Stress may generally be defined as a state of imbalance between environmental demands and the human's resources for dealing with those demands (Novaco, 1988). Stress has also been defined as a "mismatch between an individual's perception of the demands of the task or situation, and his perception of the resources he has to meet those demands" (italics added for emphasis) (Stokes and Raby, 1989). This view requires the measurement of task demands to determine the stress levels present.

One critical factor that might be placed in this task performance area is performance anxiety. Hockey (1986) had placed this factor in a class called social environment. Existing studies of anxiety have focused on test anxiety, which has been shown to be associated with performance decrements. For example, a study by the NRC (U.S. NRC SECY-91391) found that licensed operators perceived stress during simulator-based requalification exams and that many believed this stress had degraded their performance. Moreover, other investigations have reported decrements in attention and working memory on cognitive tasks under anxiety conditions (Eysenck, 1982). Wine (1971) has attributed performance decrement to a "worry" component of anxiety: behavior is disrupted by the failure to maintain attention in the face of excessive concern about the adequacy of one's performance. Klein and Zsambok (1994) have posited that "coping" activities become a secondary task that takes mental resources away from the primary task.

The Navy's Tactical Decision Making Under Stress (TADMUS) program has focused on task demands as a major source of stress (Driskell \& Salas, 1991b). Their program places all stressors in one of two categories, ambient stressors and task-related stressors. Ambient stressors include noise, heat, and fatigue (addressed in sections 2.1 and 2.2). Taskrelated stressors, which TADMUS emphasizes, are indices of task demands, primarily time pressure and workload. Workload measures attempt to quantify the amount of mental processing that must occur. These measures capture task characteristics such as sensory inputs, information available, short-term memory requirements, etc. However, it is important to distinguish between changes in task performance due to actual reduction in time available or increase in workload and changes in task performance due to stress from the perception of time pressure or perception that all tasks cannot be completed.

\subsection{Impairment Due to Stress on Cognitive Task Performance}

In addition to identifying classes of variables that increase stress levels, the research literature also identifies the types of cognitive skill performance impairments that can be attributed to increased stress levels. The following types of potential impairments in performance have been identified:

1. A narrowing and shift in attentional focus.

2. A reduced working memory capacity.

3. Time pressure effects, in one of two forms:

a. Speed-accuracy trade-offs

b. Incomplete task processing

4. Impaired crew communication patterns.

\subsubsection{Narrowing and Shift in Attentional Focus}

One of the most widely reported effects of stress on performance of cognitive tasks is that, in stressful conditions, the performer's attention becomes more narrowly focused on cues central to a task and less sensitive to the more peripheral cues. In Easterbrook's influential 1959 article, his primary claim was that "emotional arousal acts consistently to reduce the range of cues that an organism uses..." (p. 183). Easterbrook further claimed that an "improvement of central performance occurs concomitantly with impairment in effectiveness of peripheral response..." (p. 184). Thus, there is emphasis both on greater focus on the central task and reduced attention to peripheral stimuli. 
Similar concepts have been expressed by others. Hockey's review (1986) concludes that stress produces an "increased selectivity of attention in dual component tasks." (p. 38). This refers to results that show that performance on secondary tasks suffers, but performance on the primary task may be enhanced. In another case, Hockey notes that noise tends to "bias selection toward dominant aspects of the stimulus..." (p. 10). Again, he cites findings (e.g., Hockey \& Hamilton, 1970; Davies \& Jones, 1975) in which one aspect of performance is enhanced and a secondary aspect is impaired. Yet another version of this concept is put forth by Keinan (1987), whose study (described below) suggests that stress restricts the set of options that are considered.

Easterbrook's 1959 article provides a very broad review that attempts to support his claims by reviewing a number of studies on both humans and animals performing in a state of heightened arousal. In one example, Bursill (1958) found that subjects' attention to a peripheral task was reduced under high heat conditions. Each subject was asked to perform two simultaneous tasks. In the primary task, a tracking task, the subject was required to keep one pointer superimposed on a moving target. In a secondary task, the subject was to respond (by pressing a corresponding key) to the occasional illumination of one of six lights that were arranged in a semicircle between extremes of 80 degrees on either side of the central point in the display. Two temperature conditions were used, 60-70 degrees $F$ and 95-105 degrees F. Bursill found that the mostperipheral signals had a higher probability of being missed in the high-heat condition. Further, Bursill claimed that this phenomenon does not occur when the demands of the primary task are reduced. From this, Bursill concluded that the phenomenon is tied to central attentional resources and that under heat stress there is a reduction in the "field of awareness."

Mandler's (1979) review also advances the proposition that central cues become more important and peripheral cues are less likely to be used under conditions of high arousal. Mandler's review cites studies by Hockey (1970), Baddeley (1972), and Bacon (1974) that demonstrated either the enhancement of centrally attended stimuli at the expense of peripheral ones or a narrowing in the range of cues. Several of these cases (e.g., Baddeley, 1972) created a situation perceived as dangerous by the subject in order to increase the subject's level of arousal.

Thus, studies of both animals and humans converge to the finding that a heightened state of arousal leads to a narrowing and shift in attentional focus. However, there is no universally accepted account underlying this phenomenon. One hypothesis (Mandler, 1982; Keinan, 1987) is that the heightened state of arousal is distracting and requires attentional resources. Mandler (1979) claims that attentional resources must be committed to dealing with both the activation in the autonomic nervous system and the external or internal events that led to the heightened arousal. An alternative hypothesis (Easterbrook, 1959; Hockey, 1979) emphasizes a focusing or funneling of attentional resources instead of a loss of resources to a secondary task. This hypothesis suggests that the increased attention on central cues serves to reduce the perceptual field to the area of a potential threat. That is, all resources are shifted to the most critical task or environmental cues in order to be best prepared to address them. Easterbrook contends that arousal enhances the importance of central cues and expedites reaction to them.

\subsubsection{Reduced Working Memory Capacity}

A second consistent finding in studies of the effects of stress on performance is that performance is impaired when it relies heavily on working memory. Working memory, also referred to as active memory or short-term memory, is where information is temporarily stored and manipulated. Tasks that require information processing-such as arithmetic computations, deductive reasoning, spatial manipulations-typically have a large working memory component.

In Hockey's (1986) review of the effects of noise on performance, he notes that "noise reduces the effectiveness of short-term memory in tasks requiring working space for the manipulation of information (p. 10)." He then cites several studies that support this claim. Broadbent (1957) asked subjects to perform an arithmetic task that required them to hold one two-digit number in memory until a second number (the addend) was presented. The use of noise to increase stress led to a slower rate of work (i.e., longer response latencies) when compared to a nonoise condition. Hamilton, Hockey, and Rejman 
(1977) found that the impact of noise on performance of a problem-solving task depended on the degree to which working memory was involved in problem solving. As the working memory component was increased, the effect of noise shifted from being initially facilitative to being markedly inhibitory. Hockey (1986) also identified performance impairments tied to working memory when anxiety is the stressor (e.g., Hockey, McLean, \& Hamilton, 1981). In general, Mandler (1979) has commented that digit span (a standard working memory measure) is reduced by stressful situations.

Stokes and Raby (1989) developed a test battery that included tests that rely heavily on working memory (e.g., numher span, spatial reasoning) as well as tests that emphasize other cognitive abilities. Their subjects, who were novice piluts, took two parallel versions of the test battery, with one version being administered under stressful conditions. Stokes and Raby produced stress in their subjects by simultaneously applying experimental manipulations that introduced uncertainty into the task, elevated the subjects' perception of task demands, reduced the subjects' perception of their ability to cope, and emphasized the importance of success. As expected, the tests on which performance was most impaired by the stress manipulations were tests that required a significant working memory capacity.

Thus, a number of empirical investigations, using various means for producing high arousal, have shown decrements in working memory. There is, unfortunately, no good theoretical account of this effect. One possible explanation for the decrement in working memory under high arousal is the "distraction" hypothesis used to account for reduced attention. That is, working memory may also be reduced due to mental resources that are committed to dealing with the symptoms and causes of the aroused state.

As a second possibility, Hockey (1979) has suggested a trade-off relationship between storage and speed of processing. His suggestion is that a state of low arousal is better for memory storage, and that a state of high arousal is better for speeded processing of information (this refers to tasks that emphasize speed but make shallow demands on processing). Thus, during the high arousal that results from aversive noise, working memory will suffer, but simple processing will be faster. More work is needed here to validate this generalization.

\subsubsection{Time Pressure Effects}

The third general finding in studies of the effects of stress on performance is that subjects behave as though they are under time pressure. This effect can be expressed in two ways. First, performers may perform the task more quickly at the expense of a high degree of accuracy, referred to as a speedaccuracy trade-off. Second, performers under stress may give an incomplete performance by dropping, or shedding, elements of the task. Both can be detrimental to the performance of decision-making tasks. In the extreme cases where task elements are actually dropped, the decision making process can potentially produce significant errors.

Figure 2 shows the general relationship between a subject's speed of response and accuracy. An example of a task used to produce this type of curve is the choice reaction time task. In this task, a subject is presented with two corresponding arrays of buttons and lights. When a light is illuminated, the subject pushes the button corresponding to that light. Instructions emphasize both a fast response and an accurate response. Perfectly accurate performance (the upper right tail of the curve) requires much slower response times. At the other end of the curve is the shortest response time the subject can produce. However, accuracy suffers at this rate of responding. Typically, subjects will find a point between the two extremes that is slower than their fastest speed but not error-free (e.g., the point labeled 1).

Experimental manipulations (e.g., incentives, directions) can be used to shift a subject toward one of the two ends of the curve. For example, mildly punishing a subject for errors will increase response time and shift performance to the right (e.g., to the point labeled 2).

As described in the last section, Hockey (1979) suggested that performance during high arousal facilitates speeded processing. This hypothesis implies that the subject can shift toward the fastresponse end of the curve without suffering a decrement in accuracy. However, others claim that, for some tasks performed under stress, performers shift toward the speed end of the curve at the expense of accuracy--that is, there is a speedaccuracy trade-off. 
Training Approaches to Reduce Stress Effects

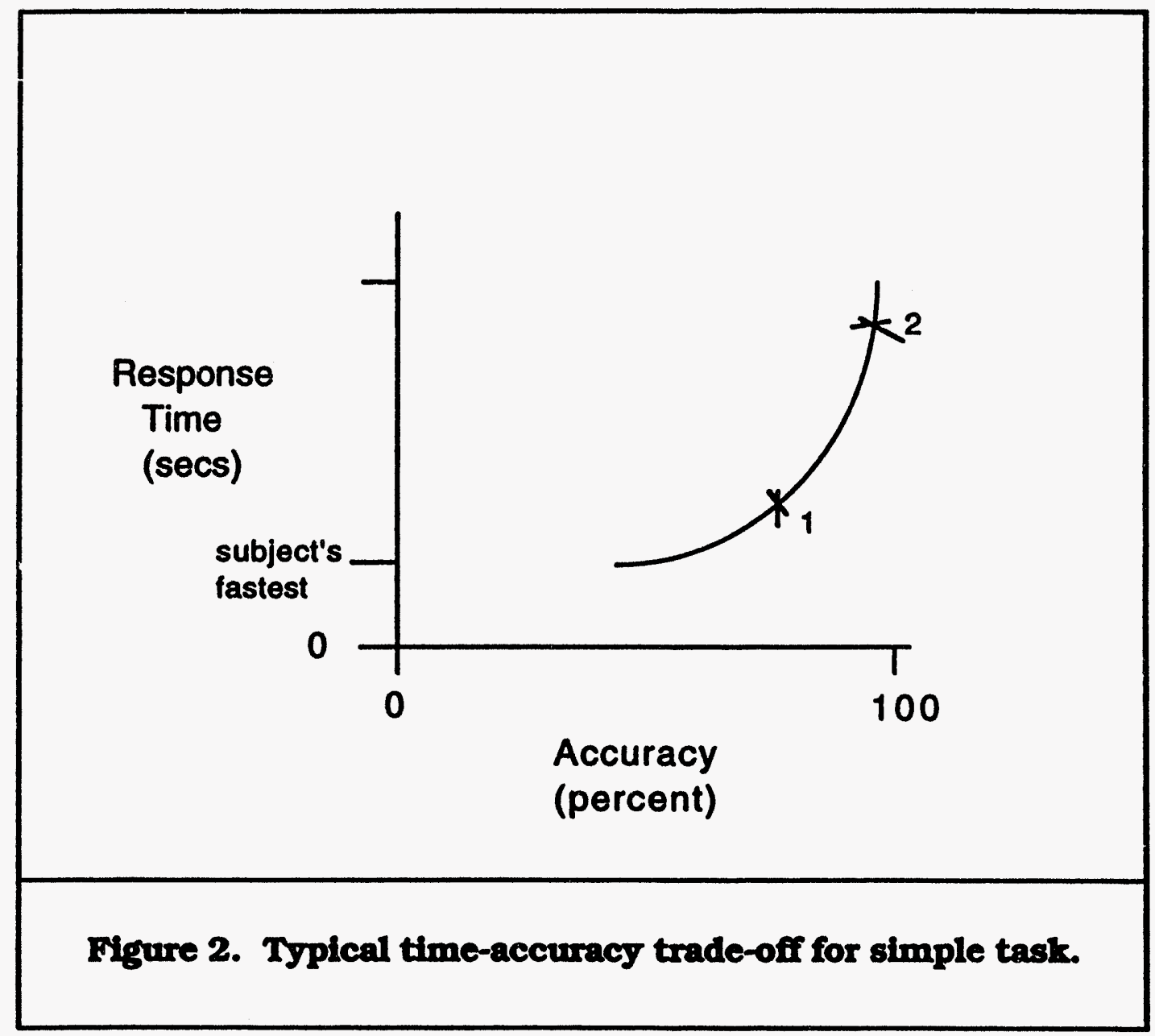


Some studies have found that, during high arousal, response times become faster with no significant decrement in accuracy (e.g., Davies \& Davies, 1975). Other studies (Broadbent, 1957; Wilkinson, 1963) have found an increase in errors without a significant speed-up of responding. Still other studies found (Blake, 1971; Hartley, 1973) a true speed-accuracy shift: faster responding and more errors. These studies manipulated arousal in a number of ways: noise, heat, loss of sleep, as well as time of day changes in arousal. In many cases, multiple arousal manipulations were used, sometimes in attempts to offset one with another. For example, noise (to increase arousal) was sometimes used to offset the effects of sleep deprivation (arousal decrease).

In some cases, the primary effect of stress on these tasks has been an increase in the number of "gap," or "block," trials (Corcoran, 1962). These are single trials with an unusually slow response time (sometimes defined as a delay of 1.5 seconds or more). The subject seems to become disengaged from the task momentarily. Pepler (1959), using high heat as a stressor, found increases in both errors and gap trials. Studies of sleep loss (usually one complete night without sleep) have shown similar results in the choice reaction time task.

Janis (1982) has collected evidence that decisionmaking performance suffers under stressful conditions. Specifically, Janis showed that stress impairs decision making by producing a hasty, disorganized, and incomplete evaluation of information, as though insufficient time exists to complete processing. Keinan (1987), following up on this hypothesis, studied the effects of stress on a decision-making task that required only scanning and consideration of decision alternatives. The task given to subjects was a verbal analogies task. Subjects were presented with an incomplete analogy, such as "butter is to margarine as sugar is to ". Subjects were then asked to examine six alternatives for completing the analogy and to select the most appropriate alternative. The subjects used buttons numbered 1-6 to select the alternatives, which were displayed one at a time on a CRT, and each alternative could be selected as often as desired. Stress was effectively induced in subjects by the threat of electrical shock (which was never actually implemented). Keinan found that those subjects under the threat of shock performed worse on this task in three ways. First, stressed subjects were incorrect on significantly more items than nonstressed subjects. Second, stressed subjects were more likely to register an answer befrre reviewing all six alternatives. Third, stressed subjects were more likely to use a non-systematic scanning pattern in reviewing alternatives. Keinan concludes from these results that stress from the threat of shock impairs decision making, at least in part, by producing a scanning strategy that is hurried, incomplete, and unsystematic. These subjects tended to behave as though they were under time pressure, though there was no link between time and threat of shock.

The Janis (1982) and Keinan (1987) studies indicate that certain task elements are processed in a shallow manner. A recent study of anesthesiologists in a trauma center setting (Mackenzie et al., 1993) suggests that some task elements may be omitted under stress. In this case, anesthesiologists performing airway management during emergency medical treatment omitted certain patient preparation and patient monitoring elements of the task. Thus, while others have shown evidence that the decision-making process can change significantly when time pressure is present (Svenson \& Maule, 1992; Means et al., 1993), it also seems that decision making may be truncated or altered under stress, even when time pressure is not present. This finding is significant for NPP performance since these decisionmaking tasks rely on thorough and systematic decision processes.

\subsubsection{Impaired Crew Communication Patterns}

This section shifts the focus from individual performance to crew performance. In general, laboratory investigations of crew performance are less common than are investigations of individual performance. Much of the evidence for crew effects comes from anecdotal reports of actual incidents in which crews were placed in highly stressful situations that led to disasters or near-disasters (e.g., Foushee \& Helmreich, 1988). More importantly, teams that are studied in the laboratory are likely to be groups of individuals brought together for the first time and have no collective work history, as opposed to actual work "crews" or "teams" who have a history of working together. Orasanu and Salas (1992) attempted to make this distinction clear by distinguishing carefully between a team and an ad hoc group. The validity of results obtained from these ad hoc groups 
must always be carefully evaluated when studying communication patterns, importance of status, and other variables that are established within an actual work setting.

Although a wide array of performance impairments have been documented in the literature, there have been few investigations of crews under stress in actual work environments to draw any strong conclusions. However, one general impairment often reported is impaired crew communication patterns.

Foushee \& Helmreich (1988) describe a number of commercial airline disasters that implicate problems in communication between the crew and the captain. They describe how, in numerous aviation disasters, crew members had important information and geve warnings or stated objections that were not heeded by the captain. In some cases, the captain seemed reluctant to take the advice, and in other cases, the crew member seemed unwilling to question the captain's authority. In either case, important information that could have prevented the disaster was not used effectively. A quote from a National Transportation Safety Board report (1979) summarizes the phenomenon:

"The Safety Board believes that this accident exemplifies a recurring problem-a breakdown of cockpit management and teamwork during a situation involving malfunctions of aircraft systems in flight. To combat this problem, responsibilities must be divided among members of the flight crew while a malfunction is being resolved... Admittedly, the stature of the captain and his management style may exert subtle pressure on his crew to conform to his way of thinking. It may hinder interaction and adequate monitoring and force another crewmember to yield his right to express an opinion. (pp. 26-27)" This quote suggests that two factors contribute to the failures in crew communication: differences in status and a poor group decision-making process. Status differences are especially relevant to aviation crews.

Driskell \& Salas (1991a) tied the Foushee and Helmreich findings into the more general hypothesis that subordinate crew members acquiesce to authority under stress. They cite other work that suggests that stress causes an organization to centralize its decision-making authority (e.g., Hermann, 1963). However, even when no strong status differences exist in a group, communication problems can emerge. Janis (1972) identified a phenomenon called "groupthink." Groupthink is characterized by a marked decrease in the exchange of discrepant or unsettlir.g information for the benefit of maintaining group harmony. Thus, a number of factors may come together during stressful situations (Holsti, 1971) that prevent crew leaders from making full use of important information that may disconfirm their current understanding of the situation.

Torrance (1967) also cites cases (e.g., from actual military settings, simulated team survival exercisus, and other group decision-making tasks) of communication failures between group members under stress. Specifically, he describes cases in which: (a) there is a failure to pool information that would provide a basis for diagnosis; (b) power differences in the group interfere with the communication of information needed in decision making; and (c) there is an unwillingness to disagree in the decisionmaking process. From these cases, Torrance draws the conclusion that "under moderate stress...there appears to be a tendency for the members of a group to polarize around a leader and to respond more precisely to his communications (p. 113)."

\subsubsection{Summary and Conclusions}

This section reviewed the empirical investigations of specific impairments of performance on cognitive tasks, both for individuals and crews. The impairments described were the following:

1. A narrowing and shift in attentional focus.

2. A reduced working memory capacity.

3. Time pressure effects.

4. Impaired crew communication patterns.

The first two of these have strong support from empirical work. The latter two have considerable support from a number of sources, but more evidence is needed to draw strong conclusions. Other performance impairments have been described in the literature, especially for crew performance, but these effects may be unique to an experimental setting or task. One effect not discussed here that seems to have widespread anecdotal support is the claim that individuals under stress freeze up or revert to stereotypical behaviors, even when they are maladaptive. The example commonly given is that 
soldiers freeze up in battle and do not fire their loaded weapons (Druckman \& Swets, 1988). There does not seem to be sufficient evidence for this claim in the literature reviewed here. It is possible, however, that this type of impairment occurs primarily under the type of severe stress conditions (e.g., battle) that are almost impossible to simulate for controlled studies.

More generally, this review revealed several weaknesses in the "stress and performance" literature. The greatest weakness is a lack of a theoretical framework. This report makes no attempt to develop an underlying theory for these effects, but only to document the empirical effects most relevant to the NPP context. While theories have been proposed by some researchers to account for certain phenomena, the full set of results within the literature has not been addressed from a single perspective.

A second weakness of the empirical work described in this section is the vast difference between the level of stress induced in the laboratory setting and the level of stress that can occur in the real world. Events such as severe accidents, military engagements, and major natural catastrophes (e.g., earthquakes) can engender extreme levels of stress. Janis (1982) describes panic attacks and the completely maladaptive behavior that can be manifested from severe fear or anxiety. Two relevant research questions are "How likely is this level of stress reactior. in key personnel?" and "What are its effects on decision making?" It is unlikely that the means for inducing stress in laboratory settings will provide an adequate test of these issues. Although some researchers have used significant threats to induce stress--e.g., Keinan (1987) used the threat of electric shock, Driskell and Salas (1991a) used the threat of tear gas--these types of manipulations are rare because they are typically considered to be unethical for human subjects. It is more typical for researchers to use reduced time or increased workload to induce stress. Means for inducing. stress in a simulated setting are explored further in Section 5.2 . 


\section{Sources of Stress in the NPP Setting}

The focus of this report is the effect of stress on NPP decision making and the cognitive skills that support it. In the analysis of SAM decision making (see NUREG/CR-6126), six major components of decision making were identified:

- Monitor / Detect - Active (monitor) and passive (detect) means for acquiring data about plant state. Sources of data are alarms, indicators, CRT displays, other individuals, etc.

- Interpret Current State - The development of a mental representation of plant status. This representation may include interpretations concerning faults and causes of abnormal symptoms, or it may be only a prioritized list of symptoms (e.g., safety violations).

- Determine Implications - The determination of how the current plant state will progress (e g., potential consequences, side effects). Also, a set of goals is defined in which more important goals are given higher priority and complex goals may be broken down into subgoals.

- Plan - The selection of a response plan, which could be a high-level action or formal procedure, that addresses the goal(s) with the nighest priority.

- Control - The coordination and execution of a specific sequence of control actions.

- Feedback - The information gained from control actions is used to update understanding.

These major components cover a wide range of cognitive skills, defined at both individual and crew levels, and may be affected by stress (see Table 1). A review of this Table reveals that these skills cover a wide range of decision-making situations: from simple decisions on data reliability and accuracy to complex mental simulations of plant phenomena and systems, and from individual decisions on procedure selection to coordination of major control actions that can involve multiple people in different sites. Further, the analysis of SAM decision making indicated that it is susceptible to increased complexity. SAM decision making may involve complex events (e.g., the need to consider side effects of corrective actions on interrelated systems), novel phenomena (e.g., core melt through containment), and unfamiliar control actions. Because of the increased complexity, stress becomes a significant factor in performance of the appropriate skills.

This section uses the three approaches for defining stress that were described in Section 2 to identify potential sources of stress in the SAM setting, or NPP setting more generally. Recall from Section 2 that the first approach to defining stress considers environmental factors; the second approach addresses the role of novelty and uncertainty; and the third approach considers task-related factors, such as workload. The outcome of this analysis is a listing of the major sources of stress (Table 2) that are likely to affect human performance on cognitive tasks.

\subsection{Environmental Factors as Sources of Stress in NPP Operations}

Recall that environmental factors were classified by Hockey (1986) into five classes:

- Physical environment - which included factors such as noise, heat and cold, vibration, lighting, and atmospheric conditions.

- Drug effects - which was broken generally into stimulants and depressants.

- Fatigue states - which included the effects of sleep deprivation and boredom that may come from prolonged performance.

- Cyclical changes - which includes regular, periodic changes in hormonal levels, alertness, body temperature, etc.

- Social environment - which addressed performance anxiety and the use of incentives.

Several of these environmental factors (e.g., noise, temperature, fatigue) may have a role as sources of stress in SAM although they are probably less important than the factors described in sections $\mathbf{3 . 2}$ (Novelty and Uncertainty) and 3.3 (Task-Related Factors). One potential source is the physical environment. Noise is always a concern during any emergency event, but other aspects of the physical environment can become relevant. For a design-basis accident (e.g., loss of coolant accident), the control room and technical support center (TSC) are well protected from environmental changes; lighting, 
Table 1. Summary of High-Level Cognitive Skills Needed for NPP Decision Making.

\section{Monitor/Detect}

1. Determine accurate indications of plant state

2. Integrate plant state indications

3. Identify meaningful events

Crew:

1. Communicate important plant state indications to the decision maker.

\section{Interpret Current State}

1. Make inferences about current plant state

2. Determine expected influences and relevant data

3. Recognize links to existing procedures and SAMG

\section{Crew:}

1. Provide crew input to interpretation process

\section{Determine Implications}

1. Use mental representation to simulate event's progression and identify goals.

2. Determine goal priorities.

3. Recognize links to existing procedures and SAMG.

Crew:

1. Provide crew input to goal identification / priority setting process.

Plan

1. Identify appropriate existing response plans.

2. Formulate response plan.

3. Evaluate response plan.

4. Determine action sequence.

Crew:

1. Provide crew input to planning process.

Control

1. Manage the execution of a response plan.

2. Execute control actions.

Crew:

1. Coordinate related control actions.

Feedback

1. Use plant state data to determine that control actions are having desired effect.

2. Evaluate appropriateness of response plan. 
temperature control, and radiation protection all depend on back-up systems.

During a severe accident, however, certain environmental factors may come into play, especially if the transient covers an extended period. For example, if there is a loss of all AC power, the plant may lose temperature control, atmospheric control, or lighting, or it may become dependent on short-term power supplies (i.e., battery). Several conditions that may be detrimental to task performance can arise. Ambient temperatures can increase gradually to make the working environment initially uncomfortable or even intolerable, and lead to increased stress levels. Lighting levels may be reduced, which would increase the difficulty in reading displays, labels, and charts and in taking the required controi actions. If a threat of radiation becomes likely, control room operators or others may be required to wear special protective gear, which can impede task performance (e.g., communication and coordination activities). Although lighting level and the use of protective clothing may not produce stress effects (there are no strong research findings to suggest it), performance can be impaired due to the increased difficulty in obtaining information and taking control actions.

A second potential source of environmental stress, especially under emergency or severe accident conditions, is fatigue attributed to prolonged work, sudden change in work shifts, or perhaps, loss of sleep. If the recovery or mitigation process extends over several days, there is opportunity for fatigue among a number of key personnel. Even if operators and TSC staff maintain shifts to a large degree, it is likely that more shift overlap will be required and that less adequate rest will occur between shifts.

\subsection{Novelty and Uncertainty as Sources of Stress in NPP Operations}

The studies described in Section 2.2 are a small part of the literature that supports the notion that uncertainty and novelty are strong mediators of a physiological stress response. As that section demonstrated, even in cases where an event's outcome cannot be controlled, the organism's foreknowledge of the outcome is tied to a reduction of the stress response. Notions of reducing stress (called coping) from this perspective are concerned with providing information that makes events more predictable, increasing the degree of control the subject has over the event's outcome, or providing feedback on how the subject's actions are affecting outcomes (even when total control is unavailable).

Although he did not address decision making in the NPP environment, potential sources of stress can be identified based on Mandler's general concepts. Thus, extending his notion of interruption theory, sources of stress in NPP emergency and severe accident situations may be any of the following (see Table 2):

- Events that are novel; e.g., because the physical phenomenon (such as core melt) is not well understood, because the likely progression of the event is not understood, or because the appropriate actions are not known immediately.

- Events in which expectations are violated; e.g., because parameters fail to trend in the expected direction, because certain indications do not fit into the current understanding, or because systems fail to work as expected.

- Events in which critical information is missing and, therefore, prediction is more difficult and outcomes are less certain; e.g., critical sensors are lost, the status of critical safety systems is unknown.

- Events in which more than one goal must be addressed. SAM can present situations in which it is critical to address more than one goal or in which the actions required to achieve one goal are in conflict with a second goal (for examples, see Appendices B and C of NUREG/CR-6126). When operators are required to select among or prioritize multiple goals, uncertainty is introduced about which actions are appropriate.

- Events in which plans or actions are not implemented successfully. Plans and procedures provide expectations about the sequence of events. Thus, when implementation is not successful, expectations are violated and uncertainty is introduced. 


\subsection{Task-Related Factors as Sources of Stress in NPP Operations}

The task-related approach to defining stress is valuable for the analysis of sources of stress in NPP operations. First, the notion of performance anxiety is relevant. Given an NPP event progresses to severe core damage, a great number of people will become involved in monitoring the decision-making process. Operators and TSC staff activities may be monitored by plant and utility management, state and local government emergency management officials, the media, and NRC regulators. Any problems or delays will be analyzed later in hindsight to reveal slips and misdiagnoses. The operators and technical staff are aware that their job, the well-being of the plant, and the safety of people in the surrounding community are dependent to a large extent on their performance. Performance anxiety of this magnitude has never been studied in a controlled setting.

However, research in social psychology (e.g., Zajonc, 1965) has shown that even an audience with no input can increase arousal in a performer. Druckman and Bjork (1991) point out that arousal facilitates performance of well-learned, routine behaviors and inhibits performance of poorly learned responses.

Second, task demands in design-basis emergency operations are very high (e.g., high number of alarms activated), and the evolution to severe accidents is likely to increase task demands (e.g., greater requirement for knowledge-based decision making) and workload for all personnel. Workload may increase for a number of reasons: greater requirement to keep others informed of event progress, increased demands for coordination with other personnel, increased monitoring of plant state, etc. It is also possible in this situation that operations will be subject to time pressure, which adds a second layer of complexity.

The difficulty in this situation is determining the degree of mismatch between task demands and human resources to meet those demands. It is not sufficient to measure task demands independently of an individual's (or crew's) ability. Thus, a situation that may be overwhelming and stress-producing for a less-experienced operator might be easily handled by a highly experienced operator. Because severe accident experience and practice in a realistic setting are infrequent, experience levels are likely to be low for these conditions. 
Table 2. Potential Sources of Stress in an NPP Setting.

\begin{tabular}{|c|c|}
\hline Approaches for Defining Stress & Potential Sounces of Stress \\
\hline Environmental Factors & $\begin{array}{l}\text { Physical Environment } \\
\text { - noise } \\
\text { - increased heat } \\
\text { Fatigue } \\
\text { - prolonged work } \\
\text { - sudden change in work shift } \\
\text { - loss of sleep } \\
\text { Drug Effects } \\
\text { Cyclical Changes }\end{array}$ \\
\hline Novelty and Uncertainty & $\begin{array}{l}\text { Novel Event } \\
\text { - physical phenomenon unknown } \\
\text { - likely event progression not known } \\
\text { - appropriate response not known } \\
\text { Expectation Violated } \\
\text { Critical Information Missing } \\
\text { Multiple Goals; Conflicting Goals } \\
\text { Unsuccessful Implementation } \\
\text { - failed plan } \\
\text { - failed control action }\end{array}$ \\
\hline Task-Related Factors & $\begin{array}{l}\text { High Workload } \\
\text { Time Pressure } \\
\text { Performance Anxiety }\end{array}$ \\
\hline
\end{tabular}




\section{Stress Effects on Performance of Cognitive Tasks}

Section 2 presented a review of the literature that identified the types of stress-related performance impairments that are likely to affect cognitive skills. In Section 3, potential sources of stress in the NPP setting were identified. This section addresses the likely effects those stressors will have on the performance of the cognitive skills that are important during NPP decision making. Impairments of individual performance and impairments of crew performance are considered.

\subsection{Impairments of Individual Performance}

Individual performance of cognitive tasks can be impaired in three ways:

1. A narrowing and shift in attentional focus.

2. A reduced working memory capacity.

3. Time pressure effects in one of two forms:

a. Speed-accuracy trade-offs

b. Incomplete task processing

\subsubsection{Narrowing and Shift in Attentional Focus}

The literature review in Section 2 showed that stress (a heightened state of arousal) can cause a performer's attention to become more narrowly focused on cues central to the task and less sensitive to the more peripheral cues. A nuclear power plant control rocm example may be drawn from operators performing important realignment tasks under emergency conditions. In this case, an operator may become more focused on parameters directly relevant to the system being realigned at the expense of more peripheral, but still critical, parameters. Thus, operators may not maintain a high skill level during important monitoring tasks.

More generally, a narrowing and shift in attentional focus, could have a negative effect when:

1. Multiple tasks need to be performed or monitored simultaneously.

2. Multiple suurces of information (control panel indications, procedural cautions, piping and instrumentation drawings, etc.) need tr. be monitored or consulted, some of which are less salient than others.

The following cognitive skills (taken from Table 1) are likely to be needed in NPP operational conditions that meet one or both of the above criteria:

- Determine accurate indications of plant state (Monitor /Detect).

- Integrate plant state indications (Monitor/Detect).

- Identify meaningful abnormal events (Monitor/Detect).

- Determine expected influences and relevant data (Interpret Current Statej.

- Manage the execution of the response plan (Control).

- Execute control actions (Control).

- Use plant state data to determine that control actions are having desired effect (Feedback).

- Evaluate appropriateness of response plan (Feedback).

\subsubsection{Reduced Working Memory Capacity}

Working memory is especially critical in cases in which a complex system must be mentally simulated (i.e., actually simulating the transient and plant response in one's mind) in order to determine potential outcomes of control actions on the system. For example, in evaluating the effects of a highlevel control action, such as depressurization or flooding, the operator may need to consider how that action will affect related systems. Mentally simulating the consequences of each system's response can incur a large computational load. In other words, working memory is likely to have a large role in decision making during emergency and severe accident situations. Working memory is also critical to the management of the overall response, where coordination is required among many different groups of people.

Generally, a reduced working memory capacity could have a negative effect when:

1. There is a heavy burden on mental simulation of plant systems or control actions.

2. There is a significant requirement for mental computation. 
3. Information from several sources needs to be integrated mentally.

4. Multiple small tasks are being managed simultaneously.

The following cognitive skills are likely to be needed in NPP operational conditions that meet one or more of the above criteria:

- Integrate plant state indications (Monitor/Detect).

- Make inferences about current plant state (Interpret Current State).

- Use mental representation to simulate event's progression and identify goals (Determine Implications).

- Determine goal priorities (Determine Implications).

- Formulate response plan (Plan).

- Evaluate response plan (Plan).

- Determine action sequence (Plan).

- Manage the execution of a response plan (Control).

- Evaluate appropriateness of response plan (Feedback).

\subsubsection{Time Pressure Effects}

Many elements of NPP decision making require extensive, systematic analyses that need to be executed completely to ensure an appropriate response.

While there are ample demonstrations that performance changes during stressful conditions, the literature on speed-accuracy trade-offs has not found a consistent pattern of changes. There is a further difficulty in extending the speed-accuracy trade-off results to the NPP context. The tasks reported on in the literature require continuous attention to a fairly mechanical task over a prolonged period, and there is no clear parallel in NPP control tasks. While there is evidence of shifts in speed-accuracy and gaps on these laboratory tasks, it is not clear how strongly these results apply to more realistic control tasks. Of greater concern is the potential for incomplete performance of critical decision-making tasks.

Time pressure effects were split into speed-accuracy trade-offs and incomplete task processing. An inappropriate speed-accuracy trade-off could have a negative effect on NPP decision making when:

1. A series of simple decisions or judgments can be executed in succession.

2. Speed of execution is not limited by the control room interface.

In this case, the only candidate cognitive skill is "execute control actions (Control)." During the execution of a series of control actions, there are opportunities for speeded processing that can lead to execution errors.

More importantly, incomplete task processing could negatively affect decision making when:

1. A thorough and/or systematic analysis is required to avoid errors.

The following cognitive skills are thus susceptible to incomplete task processing:

- Determine accurate indications of plant state (Monitor / Detect).

- Integrate plant state indications (Monitor/Detect).

- Make inferences about current plant state (Interpret Current State).

- Determine expected influences and relevant data (Interpret Current State).

- Use mental representation to simulate event's progression and identify goals (Determine Implications).

- Determine goal priorities (Determine Implications).

- Formulate response plan (Plan).

- Evaluate response plan (Plan).

- Determine action sequence (Plan).

- Manage the execution of a response plan (Control).

- Execute control actions (Control).

- Use plant state data to determine that control actions are having desired effect (Feedback).

- Evaluate appropriateness of response plan (Feedback). 


\subsection{Impairments of Crew Performance}

Crew performance must also be considered a critical component of SAM decision making and can also be affected by high levels of stress. The primary decision maker must consider inputs from multiple sources, communicate the actions that need to be implemented, and technical staff in multiple locations need to coordinate complex control actions. Research shows that these types of crew skills are susceptible to impairments from stress.

\subsubsection{Impaired Crew Communication Patterns}

Crew communication patterns could have a negative effect when important information is available only to crew mernbers (e.g., operators in the control room) and must be passed from that crew member to the primary decision maker (e.g., in the Technical Support Center).

This impairment is likely to affect all of the crewlevel cognitive skills, which are:

- Communicate important plant state indications to the decision maker.

- Provide crew input to

- interpretation

- goal identification

- priority setting

- planning

- action sequence specification

- evaluation of plan's appropriateness.

- Coordinate related control actions.

For each of these cognitive skills, it is likely that a crew member will have critical information that is less accessible or not accessible to the decision maker or another crew member that may be involved in a coordinated action. If stress impairs performance by reducing the effectiveness of the communication between crew members and crew leader, there may be performance failures. 


\section{Methods for Reducing Stress and Its Effects on Performance}

The preceding sections identified the multiple potential sources of stress within the NPP setting and suggested that these stressors are likely to impair individual and crew performance during certain stages of decision making. In this section, available methods for reducing stress and restoring performance are described. Training methods are the primary focus. However, alternate means for addressing stress and its effects exist. For example, Driskell and Salas (1991b) describe human factors engineering solutions (e.g., interface design, task structure) and personnel selection strategies (e.g., select for psychological stability) that may be effective in reducing the effects of stress. Levine (1988) identifies the existence of social support as another means of reducing the stress response. Thus, the composition of a crew and the quality of leadership can take on a role in mitigating stress (see also Fiedler \& Garcia, 1987).

Training programs designed to reduce stress generally are one of two types. Most programs are designed to address long-term effects of stress-that is, to mitigate the chronic or cumulative effects of stress to which the individual is exposed in a day-to-day setting. The second type of stress is of relatively short duration and is sudden or unexpected. Of the two, this latter type of stress is more common to the NPP context. In these situations, the individual is involved in routine, non-stressful activities one minute and then very quickly is thrust into a highly stressful setting in which skilled performance is critical. The role of a stress-reduction program in this case should be to reduce the individual's reaction to this stress and facilitate the level of performance expected in a routine setting.

It may be possible to eliminate some of the sources of stress in the NPP setting. However, because it is unlikely one can eliminate all the potential sources of stress, this section describes methods for dealing with the effects of stress in SAM. One tool that is useful for training individuals to deal with severe stress is a realistic simulation of that stressful condition. Hence, the last part of this section describes the techniques that are currently being used to simulate stressful conditions.

\subsection{Addressing the Effects of Stress through Training}

This section describes training approaches that address the effects of stress. Because there is some understanding of the types of performance impairments that are likely under stress, training approaches can be developed to mitigate those impairments. Note, as before, human factors solutions other than training are also available to address these performance impairments but are not within the scope of this report. Section 5.1.1 describes training approaches for addressing novelty and uncertainty and for task-related factors (it is difficult to identify training approaches that address environmental sources of stress). Section 5.1.2 describes training approaches for addressing specific impairments.

\subsubsection{Addressing Sources of Stress}

Novelty and uncertainty. Table 2 identified several sources of novelty and uncertainty that can contribute to stress in an NPP setting. These sources relate to novel events (such as lack of expectations concerning event progression), the violation of expectations, the absence of critical information, the existence of multiple or conflicting goals, and failed actions or plans. There are three general solutions to reducing stress from these sources:

- Increase ability to develop expectations about the event.

- Increase ability to control the event.

- Increase ability to obtain feedback concerning the success of control actions.

The primary training approach to address these abilities is exposure or guided exploration. If trainees can be exposed to some type of simulation of severe accident situations, more accurate expectations can be developed, more appropriate control actions can be mastered, and better methods for obtaining feedback can be acquired. The more realistic the simulation, the more realistic the simulated stress. As fidelity increases, trainees can learn more about the timing and frequency of alarms, the types of systems and sensors that are likely to be lost, the sequencing of malfunctions or disturbances, and even the response of certain critical parameters. 
Driskell and Salas (1991b) emphasize the use of "realistic" simulation for preparing personnel to operate in stressful environments. They cite several cases in which this type of practice has been shown to reduce stress effectively (e.g., Krahenbuhl, Marett, \& Reid, 1978; Hammerton \& Tickner, 1969). Others (e.g., Janis, 1971) have focused on simpler verbal communication of expectations, but these are often cases in which potential outcomes are easily described.

However, current NPP simulations are not able to model severe accident transients in real-time as accurately as they simulate design-basis events. Thus, while exposure through simulation can be an effective method for reducing stress, the training simulators currently available are not ideally suited for this (and the NRC does not require utilities to provide this level of simulation capability).

Simulator instructors, therefore, could use other techniques for guided exploration of severe accidents and the control room activities that accompany them as they do for other important events that are not easily simulated. For example, using non-real-time scenarios operational and technical personnel can still be exposed to the loss of indications or changes in data reliability, conflicting goals, less prescriptive procedures, or increased demands for communication.

Task-Related Factors. The sources of stress in this category concern the conditions associated with task performance: level of workload, time pressure, and stress related to one's performance being monitored. Performance is stressful to the extent that the capabilities available are not perceived to meet the demands of the task. The training approach that most directly addresses the gap between performance demands and human resources is to increase skill levels. Individuals who have mastered performance of critical tasks--who are "one step ahead" of the event--are less likely to feel overwhelmed by the task or to be insecure about others judging their performance. Specific training techniques to build the type of mastery required are addressed in Section 5.1.2.

This general approach is closely tied to the training solution offered in the preceding section, "eliminating novelty and uncertainty." In that case, exposure through realistic simulations was

discussed. That form of training should also address the development of mastery of the critical skills required for severe accident operations.

A second training approach, which offers less potential for significant reduction of stress, are stress management techniques. Novaco (1988) describes a set of techniques for recognizing and managing stress when it occurs. The focus is to help individuals recognize symptoms of stress or recognize potentially stressful situations and then deal consciously with the stress reaction. For example, time management and goal setting are two techniques for reducing the stress reaction and better addressing difficult tasks. Typically, however, these techniques require that the individual prepare for a task or that they step away from a task to prepare for performance.

\subsubsection{Addressing Stress Impairments}

Section 4 identified the performance impairments that are likely to occur under stress. The following paragraphs describe training approaches for addressing:

- High levels of arousal.

- Narrowed attention and reduced working memory.

- Poor crew communication skills.

High Levels of Arousal. A severe accident is almost certain to raise arousal levels of all involved individuals. If this arousal level becomes too high, it is likely to lead to decrements in performance. Two basic training techniques have been developed to facilitate arousal reduction: progressive relaxation and biofeedback. Progressive relaxation procedures have been described in the medical and psychological literature for more than 50 years. These techniques share the goals of reducing external stimulation, focusing on internal stimuli, slowing and regulating breathing, and relaxing muscles (Novaco, 1988).

Biofeedback is another technique used to reduce muscle tension and, therefore, arousal (Lawrence, 1984). Individuals receive information about the electrochemical activity in a muscle group (electromyography - EMG) or from the brain (electroencephalography - EEG) and attempt to reduce that activity. There is some evidence that individuals can learn to decrease the amplitude of EMG (or can increase EEG alpha). However, there is 
no evidence to indicate that biofeedback training has any effect on stress, or on performance under conditions of stress.

Narrowed Attention and Reduced Working Memory. Previous sections described one effect of stress to be narrowed attention and reduced working memory. In general, the performer has fewer mental resources that can be devoted to the task. A training approach to address this impairment is to reduce the mental resources required for skilled performance--that is, to make the performers very efficient in their use of mental resources. There are approaches to training cognitive skills that attempt to develop certain skills to the point where they are more efficient, and in some cases, minimal mental resources are required (a more detailed discussion can be found in NUREG/CR-6126).

Certain task skills can be trained to the point where they require minimal attentional resources; these skills become "automated," and this type of training is referred to as "automaticity" training (e.g., Schneider \& Fisk, 1982; Schneider \& Detweiler, 1988). Specifically, skills in which there is a consistent mapping between an event in the world and a required response can be trained in this way. In the NPP setting, one may be able to identify skills that can be trained in this way. Possible examples are reading indications, responses to alarms, interface (display) management (in computerized control rooms), or executing control action sequences. If skills such as these can be automated, mental resources can be reserved for elements of decision making that are more variable, such as planning and anticipating consequences of actions.

Training to automate certain skills early in training can aid in reducing mental demands. However, at some point, task components must be integrated, and studies have shown that automated skills may not be integrated into a dual- or multiple-task setting without a decrement in performance. Thus, there needs to be a transition to dual-task practice after the early phases of automaticity training are complete. The more general point, however, is that skills trained in isolation may be learned in an inefficient wiy. That is, when there are no other task demands, inefficient use of attentional and working memory resources can occur. Only by practicing a skill when there are additional requirements for mental resource (i.e., a second task) can the trainee learn the most efficient strategies for sharing attention and memory (Gopher et al., 1988).

Two problems can occur that would prevent efficient processing. First, in the dual-task setting there is the potential for direct interference while processing the two tasks simultaneously. For example, processing strategies for both tasks may require spatial reasoning. Through dual-task training, it may be possible to alter the processing of one of the tasks so that it becomes less dependent on spatial reasoning and more dependent on analytic reasoning. Second, the processing of a task may be inefficient because more efficient strategies have not been discovered. For example, it may be possible to achieve the same outcome with a cognitive process that uses fewer steps. Requiring trainees to perform both tasks simultaneously will often push them to discover more efficient processing on their own. To facilitate processing refinement, Schneider (1985) recommends varying the speed-accuracy requirements during practice. In some practice sessions, trainees will be pushed to emphasize speed over accuracy, and may gain in processing efficiency. In other cases, trainees may be unable to reduce processing inefficiency on their own, and these inefficiencies may have to be identified and eliminated through training targeted directly at more efficient strategies (Frederickson et al., 1983).

The importance of training in dual-task settings has been explored (e.g., Gopher, Weil, Baraket, \& Caspi, 1988). In one dual-task setting, aviation, Gopher and his colleagues conclude (a) that experience on complex tasks is insufficient to produce effective performance because many performers settle into sub-optimal strategies that support performance that, while adequate, is less than the performer's capabilities; (b) that through dual-task training, trainees can be taught attention-allocation skills, which can be transferred to new situations.

Thus, using the techniques described in this section, cognitive task performance can be made more efficient and less reliant on mental resources. This has the potential for mitigating the effects of stress on attention and working memory. Again, the overall objective is to make limited mental resources available for critical components of SAM cognitive tasks by automating some elements of task performance. 
Poor Crew Communication Skills. Section $\mathbf{4 . 2}$ identified problems in crew communication that are believed to be tied to stress. In some cases, an effective group decision-making process is not established. In other cases, status differences between crew leader and crew can lead to a communication breakdown. Crew communication and coordination skills are important elements of the larger set of crew skills. Whereas for individual skills, training was recommended to make cognitive skills less susceptible to impairments, in the case of crew skills, training needs to establish the appropriate communication and coordination skills in the NPP context. Thus, a training program is needed that identifies and trains those skills explicitly.

Only recently have crew skills been analyzed to the same level as individual skills. An intensive research program, sponsored by the Naval Training Systems Center (NTSC) and NASA-Ames, has recently undertaken the task to describe skilled crew performance. Franz, Prince, Cannon-Bowers, and Salas (1990) determined that in the area of aviation crews the following seven performance dimensions guide crew performance:

- Communication

- Situational awareness

- Decision making

- Mission analysis

- Leadership

- Adaptability / Flexibility

- Assertiveness

In a project sponsored by the NRC, a similar analysis was done for control room operator crews (see Montgomery et al., 1992). In this case, six performance dimensions were identified for describing crew performance:

- Communication

- Task coordination

- Maintaining task focus in transitions

- Adaptability

- Openness / Participation

- Team spirit

While there are differences between these two lists, there are also some striking similarities. In both cases, communication skills are considered to be critical for successful crew performance. Three important elements of communication are the identification and resolution of errors; information exchange that is accurate, clear, timely, and appropriate; and statements that are motivational or praising of other crew members (Oser, McCallum, Salas, \& Morgan, 1989). Each of these speaks to the impairments identified in Section 4.2, and each has an important role in enhancing crew performance in highly stressful situations.

As these descriptions of skilled crews have developed, a training approach has also evolved that emphasizes the most important performance dimensions. A primary objective of this approach is to address the types of crew communication problems that can occur in stressful situations. The program was initially known as cockpit resource management (CRM), or more generally, as aircrew coordination training (ACT). The most recent and most complete form of this approach, a behavior-based ACT approach, was developed at NTSC (see Prince, Chidester, Bowers, \& Cannon-Bowers, 1992). According to Prince et al. (1992), the general ACT approach can have multiple phases: awareness, practice and feedback, and reinforcement. In the awareness phase, seminars and group exercises are used to present the basic concepts of crew performance. This phase rarely provides skill practice in an operational environment.

The practice and feedback phase is best exemplified by the Line-Oriented Flight Training program (LOFT) (Lauber \& Foushee, 1981). LOFT uses realistic scenarios to involve the crew in a complex or difficult situation in which crew skills are important. For example, a full-scope, high-fidelity aircraft simulator is used to present an aircraft system failure or a weather-related problem to a full crew. The scenario typically requires the crew to execute all aspects of a mission: preparations, routine procedures, communications to individuals outside of the flight deck, etc. Crew performance is then videotaped and reviewed in a debriefing session that includes the instructor and the crew. Because these scenarios are conducted shortly after the awareness training, the crew can use them to identify areas of crew performance that can be enhanced with better communication and other aspects of crew performance. The reinforcement phase, or recurrent training phase, is a means to provide LOFT-type exercises on a recurring basis. 
Thus, every several months, the crew may conduct LOFT with review by an instructor.

Early versions of this type of program were not always well connected to specific behaviors. Thus, a behavior-based approach has been developed to make explicit the types of behaviors that indicate good crew skills. A behavior-based program seeks to identify particular behaviors within crew skill dimensions that result in effective crew performance. These are the behaviors that should be trained and evaluated. Prince et al. have recommended two basic approaches for training effective behaviors with a behavior-based ACT. First, effective behaviors can be modeled. That is, a crew could rehearse a response to a training scenario so that critical behaviors are demonstrated. Then, the instructor could work with a new crew to point out the effective behaviors as they view a videotape of the model crew. A second approach is active practice of scenarios that present opportunities for effective crew behaviors.

In an NTSC technical report (Oser, McCallum, Salas, and Morgan; 1989), researchers identified behaviors tied to crew skill dimensions while observing Navy Tactical Teams. Examples of behaviors that were characteristic of more effective crews were:

- Helped another member who was having difficulty with a task.

- Made positive statements to motivate the crew.

- Coordinated gathering of information in an effective manner.

As this work develops within the nuclear power industry, it will eventually become possible to identify behaviors that are specific to a training scenario that emphasizes high-stress situations. For example, as stress level and workload increase in a scenario, training evaluators can watch for indications that crew members continue to use effective communication skills (overcome the impairments identified above). After specific behaviors are linked with skill dimensions such as communication, those behaviors can be embedded in meaningful scenarios and a behavior-based ACT program can be established to address the performance impairments in NPP decision making.

\subsection{Methods for Simulating Stressful Conditions}

An important element of some training programs is to expose crews or individuals to realistic situations that attempt to provide a sense of the stress that may be encountered in an actual situation. This exposure is achieved through simulations of the actual situations. However, as stated above, the simulation of realistic levels of stress is difficult. Trainees know they are in a simulated setting, and their expectations for what is likely to occur may be quite different than their expectations might be in the actual setting.

Typical means for inducing stress experimentally are manipulations of time pressure, workload, and evaluation anxiety. Lanzetta (1955) and Zakay and Wooler (1984) used time pressure, as did Stokes and Raby (1989). Typically, time pressure is introduced by establishing time periods for completing a task and then presenting frequent indications that time is running out (e.g., alarms, verbal interruptions). Evaluation anxiety, which is produced by placing great importance on performance in the simulated setting, is also easy to manipulate. The importance of evaluation in certification and requalification exams within the nuclear power industry has been tied to high levels of stress (e.g., U.S. NRC SECY91-391).

Some studies have used multiple manipulations to achieve higher levels of stress. For example, Stokes and Raby (1989) manipulated five elements of the task to increase stress: they phrased the task instructions to create apprehension, used a payment method that punished errors, used a secondary task to increase mental workload, set a time limit for responding, and used a continuous loud noise.

The most extreme techniques found in the literature are cases in which subjects have been threatened with severe consequences of poor performance. In two recent examples, Driskell and Salas (1991a) used a threat of tear gas, and Keinan (1987) used a threat of electric shock in their studies of performance. In both cases, there is evidence to suggest that subjects believed they would receive these punishments if they performed inappropriately. Less severe manipulations relating to physical factors are sleep 
deprivation or other means to produce fatigue and environmental manipulations of noise and heat.

None of these methods can be identified as an overall best approach for inducing stress during training. Ideally, one should manipulate the sources of stress that are inherent in the task (e.g., realistic novel events, realistic workload increases) instead of introducing artificial factors (e.g., artificial time pressures, artificial secondary tasks to add to workload) to induce stress. Finally, when considering manipulations of stress, there are always concerns with the ethical aspects of subjecting trainees to stressful situations.

\subsection{Summary}

In this section, several training techniques for mitigating the effects of stress on the performance of cognitive skills were identified:

- Expose the crew to realistic severe accident events through a simulation - Realistic simulation can aid personnel in developing expectations about the event, skills for controlling the event, and skills for obtaining feedback concerning the success of control actions. This approach primarily removes novelty and uncertainty, which are likely to be major contributors to stress. Note that complete realism may not be possible because of the limitations in current simulation models. However, as noted above, it may be possible to simulate effectively several key aspects of the situation (e.g., data uncertainty).

- Reduce the need for mental resources and make processing more efficient - A number of training techniques exist that can make personnel more efficient information processors and reduce the demands on attention and working memory.

- Enhance crew communication and coordination skills - Crew training techniques have been refined and have been successfully used for enhancing crew skills, especially skills for communication. These techniques target the types of communication failures that are likely to occur under stress.

In general, these approaches to training attempt to develop more highly skilled personnel. When the necessary cognitive skills become mastered at a high level of performance, personnel are less susceptible to the likely effects of stress. There are a number of positive outcomes:

- Novelty and uncertainty are removed or greatly reduced.

- Operators and technical staff better understand what effect their control actions will have.

- Operators and technical staff can better cope with (and maybe stay ahead of) task demands.

- The crew shares and uses critical information better.

- There is generally a stronger feeling of control.

Other approaches to training stress-coping skills exist. The vast majority of stress-coping programs address more long-term, cumulative effects of dayto-day stress. These are not appropriate to the present context in which the individual is involved in routine, non-stressful activities, and then, may quickly be thrust into a highly stressful setting in which skilled performance is critical. The role of a stress-reduction program in this case should be to reduce the individual's reaction to this stress and facilitate the level of performance expected in a routine setting. Arousal reduction techniques were addressed but were determined to be of little use in the demanding environment of an NPP control room or Technical Support Center.

Finally, it is important to note again that training solutions are but one alternative to managing stress and facilitating performance. Human factors design approaches are likely to be effective for addressing some effects of stress. For example, the requirements for working memory may be more easily reduced through a redesign of a display device or the development of a decision aid than by a training program. 


\section{References}

Bacon, S.J. (1974). Arousal and the range of cue utilization. Joumal of Experimental Psychology, 102, 8187.

Baddeley, A.D. (1972). Selective attention and performance in dangerous environments. British Jourmal of Psychology, 63, 537-546.

Bartlett, F.C. (1943). Fatigue following highly skilled work. Procedings of the Royal Society (B). 131, 147-257.

Blake, M.J.F. (1971). Temperament and time of day. In W.P. Colquhoun (ed.), Biological rhythms and human behavior. London: Academic Press.

Broadbent, D.E. (1957). Effects of noises of high and low frequency on behaviour. Ergonomics, 1, 21-29.

Broadbent, D.E. (1979). Human performance in noise. In C.M. Harris (ed.), Handbook of noise control. New York: McGraw-Hill.

Bursill, A.E. (1958). The restriction of peripheral vision during exposure to hot and humid conditions. Quarterly Joumal of Experimental Psychology, 10, 113129.

Carlson, R.A., Sullivan, M.A., \& Schneider, W. (1989). Component fluency in a problem-solving context. Human Factors, 31, 489-502.

Coe, C.L., Stanton, M.E., \& Levine, S. (1983). Adrenal responses to reinforcement and extinction: Role of expectancy vs instrumental responding. Behavioral Neuroscience, 97, 654-657.

Coover, G.D., Ursin, H., \& Levine, S. (1973). Plasma corticosterone levels during active avoidance learning in rats. Journal of Personality and Social Psychology, 82, 170-174.

Corcoran, D.W.J. (1962). Noise and loss of sleep. Quarterly Journal of Experimental Psychology, 14, 178182.

Davies, A.D.M., \& Davies, D.R. (1975). The effects of noise and time of day upon age differences in performance at two checking tasks. Ergonomics, 4, 321-336.

Davies, D.R., \& Jones, D.M. (1975). The effects of noise and incentives upon attention in short-term memory. British Journal of Psychology, 66, 61-68.

Dess, N.K., Linwick, D., Patterson, J., Overmier, J.B., \& Levine, S. (1983). Immediate and proactive effects of controllability and predictability on plasma cortisol responses to shocks in dogs. Behavioral Neuroscience, 97, 1005-1016.

Driskell, J.E., \& Salas, E. (1991a). Group decision making under stress. Journal of Applied Psychology, 76, 473-78.

Driskell, J.E., \& Salas, E. (1991b). Overcoming the effects of stress on military performance: Human factors, training, and selection strategies. In R. Gal and A.D. Mangelsdorff (eds.), Handbook of military psychology. New York: John Wiley and Sons.

Druckman, D., \& Bjork, R.A. (1991). In the mind's eye: Enhancing human performance. Washington, DC: National Academy Press.

Druckman, D., \& Swets, J.A. (1988). Enhancing human performance: Issues, theories, and techniques.

Washington, DC: National Academy Press.

Easterbrook, J.A. (1959). The effect of emotion on cue utilization and the organization of behavior.

Psychological Review, 66, 183-201.

Eysenck, M.W. (1982). Attention and arousal: Cognition and performance. Berlin: Springer-Verlag.

Fiedler, F.E., \& Garcia, J.E. (1987). New approaches to effective leadership: Cognitive resources and organizational performance. New York: John Wiley \& Sons.

Fisk, A.D., \& Lloyd, S.J. (1988). The role of stimulusto-rule consistency in learning rapid application of spatial rules. Human Factors, 30, 35-49. 
Foushee, H.C., \& Helmreich, R.L. (1988). Group interaction and flight crew performance. In E.L. Wiener \& D.C. Nagel (eds.), Human factors in aviation. San Diego, CA: Academic Press.

Pranz, T.M., Prince, C., Cannon-Bowers. J.A., \& Salas, E. (1990). The identification of aircrew coordination skills. Paper presented at the 12th annual Department of Defense Symposium, Colorado Springs, $C O$.

Frederickson, J.R., Weaver, P.A., Warren, B.M., Gillotte, H.P., Roseberry, A.S., Freeman, B., \& Goodman, L. (1983). A componential approach to training reading skills. (Final Report 5295 ). Cambridge, MA: Bolt, Beranek, and Newman.

Gopher, D., Weil, M., Bareket, T., \& Caspi, S. (1988). Fidelity of task structure as a guiding principle in the development of skill trainers based on complex computer games. Paper presented at the annual meeting of the Human Factors Society, Anaheim, CA.

Hamilton, P., Hockey, G.R.J., \& Rejman, M. (1977). The place of the concept of activation in human information processing theory. In S. Dornic (ed.), Attention and performance, Vol. 6. New York: Academic Press.

Hammerton, M., \& Tickner, A.H. (1969). An investigation into the effects of stress upon skilled performance. Ergonomics, 12, 851-855.

Hartley, L.R. (1973). Effects of noise or prior performance on serial reaction. Journal of Experimental Physiology, 101, 255-261.

Helmreich, R.L., Chidester, T.R., Foushee, H.C., Gregorich, S., \& Wilhelm, J.A. (1989). How effective is Cockpit Resource Management Training: Issues in evaluating the impact of programs to enhance crew coordination. (NASA/UT Tech. Rep. No. 89-2, Draft 6.0). Moffett Field, CA: NASA Ames Research Center.

Helmreich, R.L., \& Wilhelm, J.A. (1986). Evaluating CRM training: I. Measures and methodology.

(NASA/UT Tech. Rep. No. 86-8). Moffett Field, CA: NASA Ames Research Center.

Hermann, C.F. (1963). Some consequences of crises which limit the viability of organizations.

Administrative Science Quarterly, 8, 61-82.
Hiroto, D.S. (1974). Locus of control and learned helplessness. Journal of Experimental Psychology, 102, 187-93.

Hockey, G.R.J. (1970). Effect of loud noise on attentional selectivity. Quarterly Journal of Experimental Psychology, 22, 28-36.

Hockey, G.R.J. (1979). Stress and the cognitive components of skilled performance. In V. Hamilton \& D. M. Warburton (Eds.), Human stress and cognition: An information-processing approach. Chichester: Wiley.

Hockey, G.R.J. (1986). Changes in operator efficiency as a function of environmental stress, fatigue, and circadian rhythms. In K. Boff, L. Kaufman, \& J. Thomas (Eds.), Handbook of Perception and Human Performance. New York: John Wiley and Sons.

Hockey, G.R.J., \& Hamilton, P. (1970). Arousal and information selection in short-term memory. Nature, 226, 886-887.

Hockey, G.R.J., McLean, A., \& Hamilton, P. (1981). State changes and the temporal patterning of component resources. In J. Long \& A.D. Baddeley (eds.), Attention and performance, Vol. 9. Hillsdale, N]: Erlbaum.

Holsti, O.R. (1971). Crisis, stress, and decision making. International Social Science Journal, 23, 53-67.

Jacobson, E. (1938). Progressive relaxation. Chicago: University of Chicago Press.

Janis, I.L. (1971). Stress and frustration. New York: Harcourt.

Janis, I.L. (1972). Victims of groupthink: A psychological study of foreign policy decisions and fiascoes. Boston: Houghton.

Janis, I.L. (1982). Decision making under stress. In L. Goldberger \& S. Breznitz (eds.), Handbook of stress: Theoretical and clinical aspects. New York: Free Press.

Keinan, G. (1987). Decision making under stress: Scanning of alternatives under controllable and uncontrollable threats. Journal of Personality and Social Psychology, 52, 639-644. 
Klein, G., \& Zsambok, C.E. (1994). The effect of acute stressors on decision making. In J.E. Driskell and E. Salas (eds.), Stress and human performance, Hillsdale, NJ: Erlbaum.

Krahenbuhl, G.S., Marett, J.R., \& Reid, G.B. (1978). Task specific simulator pre-training and in-flight stress of student pilots. Aviation, Space, and Environmental Medicine, 49, 1107-1110.

Lanzetta, J.T. (1955). Group behavior under stress. Human Relations, 8, 29-52.

Lauber, J.K., \& Foushee, H.C. (1981). Guidelines for line-oriented flight training. (Tech. Rep. No. NASA CP2184). Moffett Field, CA: NASA Ames Research Center.

Lawrence, G.H. (1984). Biofeedback and performance: An update. (Technical Report 658). Alexandria, VA: U.S. Army Research Institute for the Behavioral and Social Sciences.

Lazarus, R.S. (1966). Psychological stress and the coping process. New York: McGraw-Hill.

Levine, S. (1978). Cortisol changes following repeated experiences with parachute training. In $\mathbf{H}$. Ursin, E. Baade, and S. Levine (eds.), Psychobiology of stress: A study of coping men. New York: Academic Press.

Levine, S. (1988). Stress and performance. Washington, DC: National Academy Press.

Mackenzie, C.F., Horst, R.L., Mahaffey, D.L. et al. (1993). Group decision making during trauma patient resuscitation and anesthesia. In the Proceedings of the 37th Annual Meeting of the Human Factors and Ergonomics Society. Santa Monica, CA: Human Factors and Ergonomics Society.

Mandler, G. (1979). Thought processes, consciousness, and stress. In V. Hamilton \& D. M. Warburton (Eds.), Human stress and cognition: An information-processing approach. Chichester: Wiley.

Mandler, G. (1982). Stress and thought processes. In L. Goldberger \& S. Breznitz (eds.), Handbook of stress: Theoretical and clinical aspects. New York: Free Press.
Means, B., Salas, E., Crandall, B., \& Jacobs, T.O. (1993). Training decision makers for the real world. In G.A. Klein, J. Orasanu, R. Calderwood, and C.E. Zsambok (eds.), Decision making in action: Models and methods. Norwood, N]: Ablex.

Montgomery, J.C., Gaddy, C.D., Lewis-Clapper, R.C., Hunt, S.T., Holmes, C.W., Spurgin, A.J., Toquam, J.L., \& Bramwell, A. (1992). Team skills evaluation criteria for nuclear power plant control room crews. Working Draft.

Mumaw, R.J., \& Roth, E.M. (1992). Phase II application of THERP to the Zion human reliability analysis. (STC Report 92-5SW1-HCECO-R1). Pittsburgh, PA: Westinghouse STC.

Mumaw, R.J., Swatzler, D., Roth, E.M., \& Thomas, W.A. (1993). Cognitive skill training for nuclear power plant operational decision making. (NUREG/CR-6126). Washington, DC: U.S. Nuclear Regulatory Commission.

National Transportation Safety Board (1979). Aircraft accident report: United Airlines, Inc., McDonnell-Douglas DC-8-61, N8082U, Portland, OR, December 28, 1978 (Report No. NTSB-AAR-79-7). Washington, DC: NTSB.

Novaco, R.W. (1988). Stress reduction programs. Washington, DC: National Academy Press.

Orasanu, J., \& Salas, E. (1992). Team decision making in complex environments. In G. Klein, J. Orasanu, $R$. Calderwood, and C.E. Zsambok (eds.), Decision making in action: Models and methods. Norwood, NJ: Ablex.

Oser, R., McCallum, G.A., Salas, E., \& Morgan, B.B. (1989). Toward a definition of teamwork: An analysis of critical team behaviors. (Technical Report 89-004). Orlando, FL: Naval Training Systems Center.

Pepler, R.D. (1959). Warmth and lack of sleep: Accuracy or activity reduced. Jurmal of Comparative and Physiological Psychology, 52, 446-450.

Prince, C., Chidester, T.R., Bowers, C., \& CannonBowers, J. (1992). Aircrew coordination: Achieving teamwork in the cockpit. In R.W. Swezey and E. Salas (eds.), Teams: Their training and performance.

Norwood, NJ: Ablex. 
Resson, J. (1990). Human error. Cambridge: Cambridge University Press

Schneider, W. (1985). Training high-performance skills: Fallacies and guidelines. Human Factors, 27, 285-300.

Schneider, W., \& Detweiler, M. (1988). The role of practice in dual-task performance: Toward workload modeling in a connectionist/control architecture. Human Factors, 30, 539-566.

Schneider, W., \& Fisk, A.D. (1982). Concurrent automatic and controlled visual search: Can processing occur without resource cost? Journal of Experimental Psychology: Learming, Memory, and Cognition, 8, 261-278.

Schneider, W. \& Shiffrin, R.M. (1977). Controlled and automatic human information processing: $I$. Detection, search, and attention. Psychological Review, 84, $1-66$.

Seligman, M.E.P. (1975). Learned helplessness: On depression, development, and death. San Francisco: W.H. Freeman.

Selye, H. (1936). A syndrome produced by diverse nocuous agents. Nature, 138, 32.

Stokes, A. F., \& Raby, M. (1989). Stress and cognitive performance in trainee pilots. In Proceedings of the Human Factors Society. Santa Monica, CA: Human Factors Society.

Svenson, O., \& Maule, J. (1992). Time pressure stress in human judgment and decision making. New York: Plenum.

Swain, A.D., \& Guttmann, H.E. (1983). Handbook of human reliability analysis with emphasis on nuclear power plant applications. (Final Report NUREG/CR 1278-F). Albuquerque, NM: Sandia National Laboratories.

Torrance, E.P. (1967). A theory of leadership and interpersonal behavior under stress. In L. Petrullo \& B.M. Bass (eds.), Leadership and interpersonal behavior. New York: Holt.
U.S. Nuclear Regulatory Commission (1991). Results of the study of requalification examination stress. SECY91-391. Washington, DC: USNRC.

Wallace, R.K. (1970). The physiological effects of transcendental meditation. Los Angeles: Students International Meditation Society.

Willkinson, R.T. (1963): Interaction of noise with knowledge of results and sleep deprivation. Joumal of Experimental Psychology, 66, 332-337.

Wine, J. (1971). Test anxiety and direction of attention. Psychological Bulletin, 76, 92-104.

Yerkes, R.M., \& Dodson, J.D. (1908). The relation of strength of stimulus to rapidity of habit formation. Joumal of Comparative and Neurological Psychology, 18, 459-482.

Zajonc, R.B. (1965). Social facilitation. Science, 149, 269-274.

Zakay, D., \& Wooler, S. (1984). Time pressure, training, and decision effectiveness. Ergonomics, 27, 273-284. 

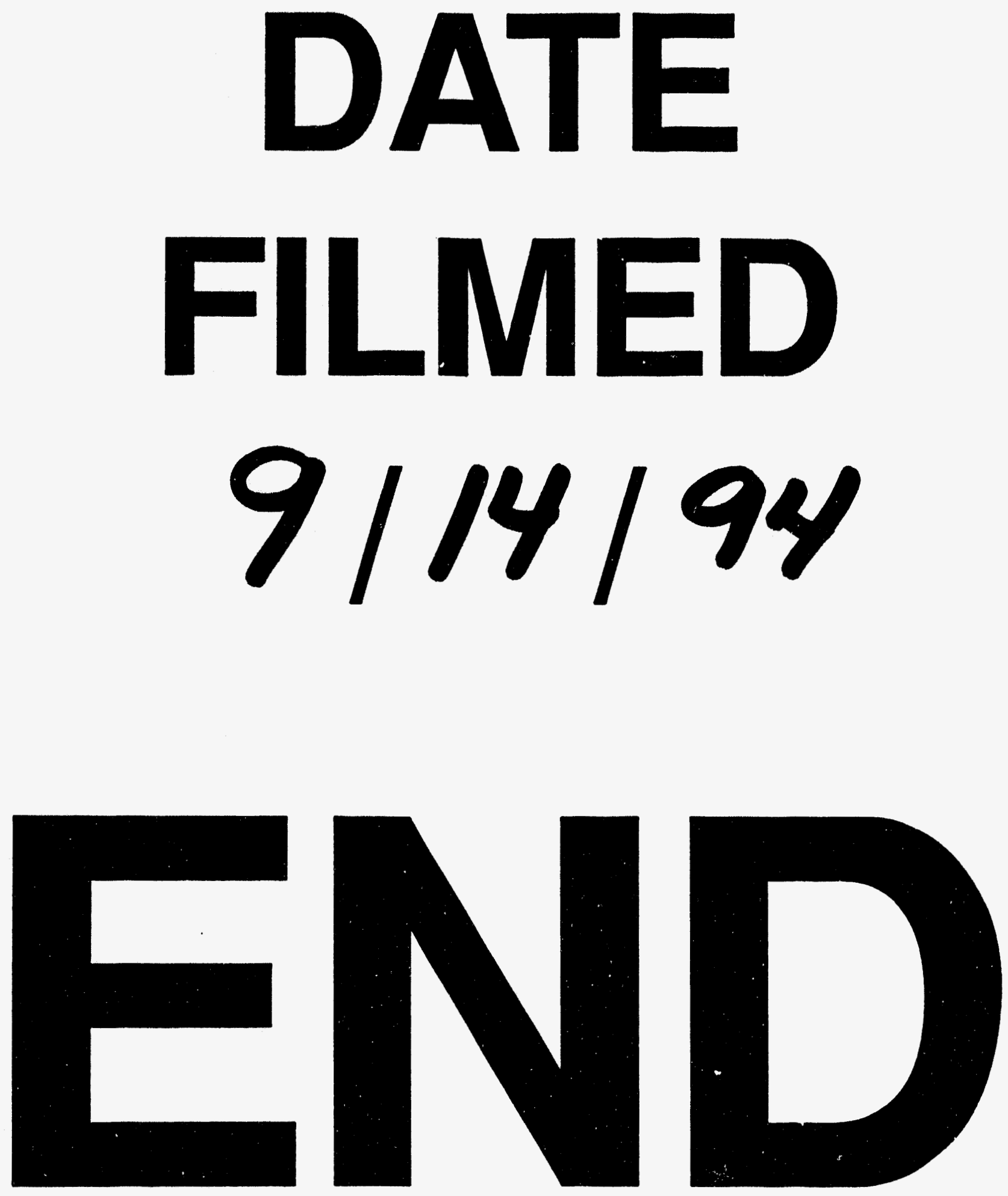

III 